\title{
Extreme Daily Rainfall in Central-Southern Chile and Its Relationship with Low-Level Horizontal Water Vapor Fluxes ${ }^{\mathscr{a}}$
}

\author{
Raúl A. VAlenzuela And RenÉ D. GARREAud \\ Department of Geophysics, Center for Climate and Resilience Research, University of Chile, Santiago, Chile
}

(Manuscript received 13 February 2019, in final form 30 May 2019)

\begin{abstract}
Extreme rainfall events are thought to be one of the major threats of climate change given an increase of water vapor available in the atmosphere. However, before projecting future changes in extreme rainfall events, it is mandatory to know current patterns. In this study we explore extreme daily rainfall events along central-southern Chile with emphasis in their spatial distribution and concurrent synoptic-scale circulation. Surface rain gauges and reanalysis products from the Climate Forecast System Reanalysis are employed to unravel the dependency between extreme rainfall and horizontal water vapor fluxes. Results indicate that extreme rainfall events can occur everywhere, from the subtropical to extratropical latitudes, but their frequency increases where terrain has higher altitude, especially over the Andes Mountains. The majority of these events concentrate in austral winter, last a single day, and encompass a north-south band of about $200 \mathrm{~km}$ in length. Composited synoptic analyses identified extreme rainfall cases dominated by northwesterly (NW) and westerly (W) moisture fluxes. Some features of the NW group include a $300-\mathrm{hPa}$ trough projecting from the extratropics to subtropics, a surface-level depression, and cyclonic winds at $850 \mathrm{hPa}$ along the coast associated with integrated water vapor (IWV) $>30 \mathrm{~mm}$. Conversely, features in the $\mathrm{W}$ group include both a very weak 300 -hPa trough and surface depression, as well as coastal westerly winds associated with IWV $>$ $30 \mathrm{~mm}$. About half of extreme daily rainfall is associated with an atmospheric river. Extreme rainfall observed in W (NW) cases has a strong orographic (synoptic) forcing. In addition, W cases are, on average, warmer than NW cases, leading to an amplified hydrological response.
\end{abstract}

\section{Introduction}

The study of weather extremes has received increasing attention in recent decades, not only because their scientific importance, but mainly because their disproportionally large societal impacts (Meehl et al. 2000). Among extreme weather phenomenon, extreme rainfall is one that can cause immediate losses through floods and landslides in both urban and rural settings. For instance, $84 \%$ of economic losses, $79 \%$ of natural disasters, and $54 \%$ of reported deaths between 1970 and 2012 were associated with extreme floods and storms globally, although their impact varies widely among countries (WMO 2014). Broadly speaking, extreme

\footnotetext{
Supplemental information related to this paper is available at the Journals Online website: https://doi.org/10.1175/JHM-D-190036.s1.
}

Corresponding author: Raúl A. Valenzuela, rvalenzuela@dgf. uchile.cl rainfall can result from either high precipitation rates in short periods of time or excessive daily (or multiday) accumulations. In regions of high terrain, average precipitation can cause major floods if accompanied by unusually warm temperatures that increase the fraction of the catchments receiving rain (Garreaud 2013). Likewise, large antecedent precipitation can saturate the soil, producing favorable conditions for flooding (Grillakis et al. 2016). Extreme rainfall events have a component of natural variability that provides the baseline for the frequency and magnitude of their occurrence. In addition, it is expected that increasing atmospheric water vapor associated with a global increase in mean surface temperature will produce both more frequent and stronger extreme rainfall events in the future (Trenberth 2011). Therefore, to understand future changes it is mandatory examining past patterns of extreme rainfall events regionwide, considering its specific climate, geographical, and human context.

One way to produce extreme rainfall is by mechanically forcing the ascent of a strong low-level water vapor flux over steep terrain. The term atmospheric 
river (AR) is employed to distinguish when this water vapor flux concentrates in elongated and narrow corridors in association with surface cold-frontal dynamics (Ralph et al. 2005; Gimeno et al. 2015; American Meteorological Society 2019). Many studies have shown a link between ARs and extreme rainfall, highlighting their importance in the hydrological cycle and as a natural hazard (e.g., Lavers and Villarini 2013; Ramos et al. 2015; Azad and Sorteberg 2017; Waliser and Guan 2017). As identified in the global climatology of Guan and Waliser (2015), there are several AR "hot spots," places where ARs hit coastal areas frequently through the year. Their study showed that one of the hot spots is along the coast of southern Chile, which motivated to Viale et al. (2018) to build an automatic identification algorithm for studying ARs along the west coast of southern South America. After applying the algorithm to a global reanalysis between 2001 and 2016, Viale et al. (2018) concluded that ARs make landfall along Chile more frequently between $38^{\circ}$ and $45^{\circ} \mathrm{S}$ (over 20 days of ARs per year in average).

ARs contribute to about $50 \%$ of the annual precipitation in central-southern Chile not only because of their frequent arrival but also because of the country's sharp and complex topography. All along the country $\left(17^{\circ}-53^{\circ} \mathrm{S}\right)$ the Andes Cordillera runs continuously within $200 \mathrm{~km}$ from the coast, rising to over $4000 \mathrm{~m}$ above mean sea level (MSL) at subtropical latitudes. At about $38^{\circ} \mathrm{S}$ the Andes height decreases significantly but many peaks still surpass $2000 \mathrm{~m}$ MSL. In addition to the Andes, a welldefined coastal range is found between $33^{\circ}$ and $42^{\circ} \mathrm{S}$ with its top between 500 and $1000 \mathrm{~m}$ MSL, only interrupted for a few major rivers that originate in the Andes. Between the coastal range and the Andes foothills there is a long, narrow central valley that concentrates much of the country's population and features a climate that varies from semiarid in the north to humid in the south.

One of the main synoptic-scale drivers of weather in central-southern Chile is coastward traveling baroclinic instabilities embedded in the Southern Hemisphere storm track between $40^{\circ}$ and $50^{\circ} \mathrm{S}$ (Trenberth 1991; Hoskins and Hodges 2005). During summertime, the southeast Pacific anticyclone strengthens and moves poleward, preventing the equatorward-curving progression of cold fronts and concentrating the rainfall in southern Chile $\left(37^{\circ}-45^{\circ} \mathrm{S}\right)$. During wintertime, some of these storms are able to reach central Chile $\left(30^{\circ}-36^{\circ} \mathrm{S}\right)$ in the form of cold fronts as the southeast Pacific anticyclone weakens and retreats equatorward (Saavedra and Foppiano 1992; Saavedra et al. 2002; Garreaud 2009).

Falvey and Garreaud (2007) examined daily rainfall for 10 winter seasons between 1993 and 2002 in central Chile. Considering a regional precipitation metric, they determined that heavy rainfall tends to occur more often in the warm, prefrontal sector of approaching extratropical storms in association with anomaly high fluxes of water vapor. Later, Viale and Norte (2009) concluded that 14 of the 15 heaviest storms between 1967 and 1976 presented anomalous westerly winds, suggesting the importance of moist upslope flows favoring these events. The study of Viale and Nuñez (2011) examined 7 years of winter rainfall in centralsouthern Chile, highlighting the role of deep extratropical cyclones and northwesterly winds in producing extreme rainfall events. The authors noted that the majority of the extreme events were associated with ARs, while a smaller fraction was linked to cutoff lows and post-cold-frontal environment. More recently, Garreaud (2013) studied 22 warm winter-storm cases in central-southern Chile, finding that strong zonally oriented jets aloft and relatively warm and moist conditions near the surface (frequently associated with ARs), were conducive to more severe moist upslope flow effect and larger rainfall accumulation over the western slope of the Andes. In contrast, 44 cold cases were associated with high-amplitude troughs extending to the subtropics and pre-cold-frontal instability produced the largest rainfall accumulations along the equatorward-curving cold front. Garreaud (2013) also highlighted the relevance of the air temperature in the overall hydrological response of a winter storm in central Chile, due to the freezing-level ranges between 2000 and $4000 \mathrm{~m}$ MSL and the Andes Cordillera surpassing $5000 \mathrm{~m}$ MSL in this region.

The previous studies have employed regional-scale metrics of precipitation (e.g., multistation average), and the number of years included are still within the natural variability domain. As a result, a longer-term and detailed characterization of extreme rainfall events in central-southern Chile is still needed. For example, where do extreme events tend to be located? Is there any seasonal change in this pattern? Is how far an extreme rainfall event impacts relative to a given location? And what is the mean synoptic pattern that drives extreme rainfall in westerly and northwesterly wind situations? The present study addresses these questions, expanding previous studies by considering extreme rainfall observations for over 300 surface stations covering 20-60 years and using reanalysis products to associate extreme rainfall with moisture fluxes. The results of this synoptic climatology also will provide context for individual storms in the past or when considering their changes in the future.

Section 2 describes the data and methods employed in the present study. A background about the climatology of rainfall in central-southern Chile is presented in 
section 3, while an empirical multilinear relationship between moisture fluxes and extreme rainfall is provided in section 4 . Section 5 addresses the mean synoptic-scale pattern linked with extreme rainfall. Section 6 discusses some hydroclimatic implications. Finally, concluding remarks of this study are presented in section 7 .

\section{Data and methods}

Daily precipitation observations were retrieved from the Center for Climate and Resilience Research (CR2). The CR2 database consists of daily rainfall observations from 872 surface stations compiled from two Chilean agencies: Dirección General de Aguas and Dirección Meteorologica de Chile (Center for Climate and Resilience Research 2018). Daily rainfall is accumulated from 1200 UTC of the reported day to 1200 UTC of the next day. Some stations have records from 1950, and the majority have records until 2017. Stations between $26^{\circ}$ and $45^{\circ} \mathrm{S}$ with at least 20 years of observations and a maximum of 73 missing days per year (i.e., 20\%) were selected, obtaining 347 stations (Fig. 1). Because there was a variable number of available years per stations (between 20 and 60 years), a 20 -yr random sampling with replacement was repeated 50 times to obtain annual average statistics for each station.

Reanalyses products from the Climate Forecast System Reanalysis (CFSR) provided 6-hourly synoptic pressure-level fields (geopotential height, specific humidity, and wind components) from 1979 to 2017 at a $0.5^{\circ} \times 0.5^{\circ}$ latitude-longitude grid resolution (Saha et al. 2010). Integrated water vapor (IWV) and integrated water vapor transport (IVT) were derived using

$$
\begin{aligned}
& \mathrm{IWV}=\frac{1}{g} \int_{P_{\mathrm{sfc}}}^{100 \mathrm{hpa}} q d p, \\
& \mathrm{IVT}=\frac{1}{g} \int_{P_{\mathrm{scc}}}^{100 \mathrm{hpa}} q \mathbf{V} d p,
\end{aligned}
$$

where $g$ is the gravitational acceleration, $q$ is the specific humidity, $\mathbf{V}$ is the total wind vector, and $p$ is pressure. To be consistent with the daily rainfall observations, daily IWV and IVT statistics from CFSR were derived by using five 6-h steps spanning the same period as the rainfall accumulation (e.g., 1200, 1800 UTC of the reported day and 0000,0600 , and 1200 UTC of the following day). In addition, a $0.05^{\circ} \times 0.05^{\circ}$ downscaled daily precipitation product derived from ERA-Interim and produced by CR2 (CR2MET; Alvarez-Garreton et al. 2018) was employed to examine precipitation patterns were surface stations are scarce or absent, such

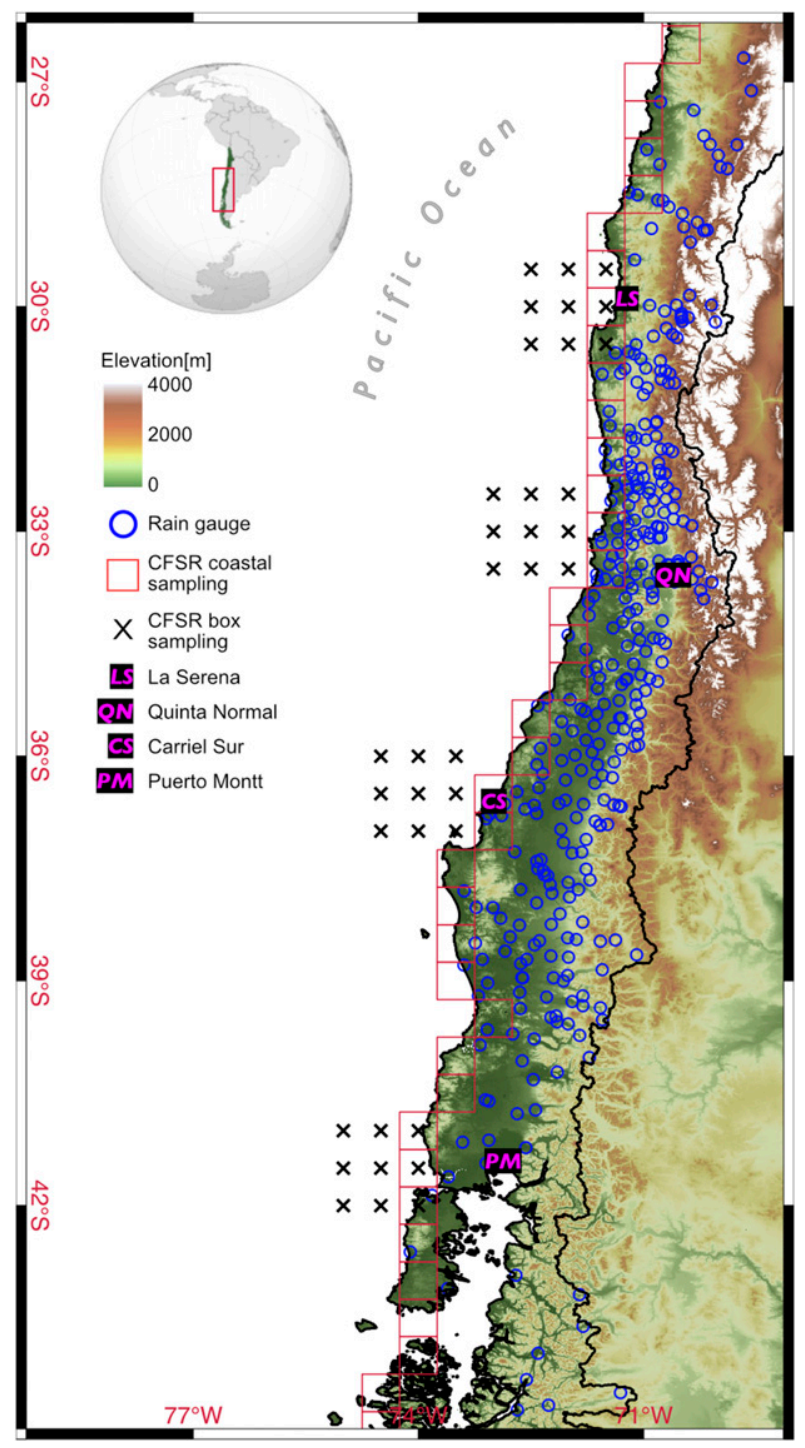

FIG. 1. Study domain including rain gauges (blue dots) and key locations of grid points extracted from the CFSR dataset: $1.5^{\circ} \times 1.5^{\circ}$ latitude-longitude boxes (black crosses) and coastal grid points (red squares). Orographic altitude is color coded, and reference locations are included: La Serena (LS), Quinta Normal (QN), Carriel Sur (CS), and Puerto Montt (PM).

as over the Andes mountain. CR2MET daily precipitation has the same convention as the daily rainfall observations.

\section{Extreme precipitation events in central-southern Chile}

\section{a. Climatological context}

Before we analyze the extreme precipitation pattern, this section provides a brief background of the centralsouthern Chile precipitation regime. Figure 2a shows 


\section{Average annual statistics for daily rainfall (WET days $\geq 1 \mathrm{~mm} ;$ EPE days $\geq 35 \mathrm{~mm}$ )}

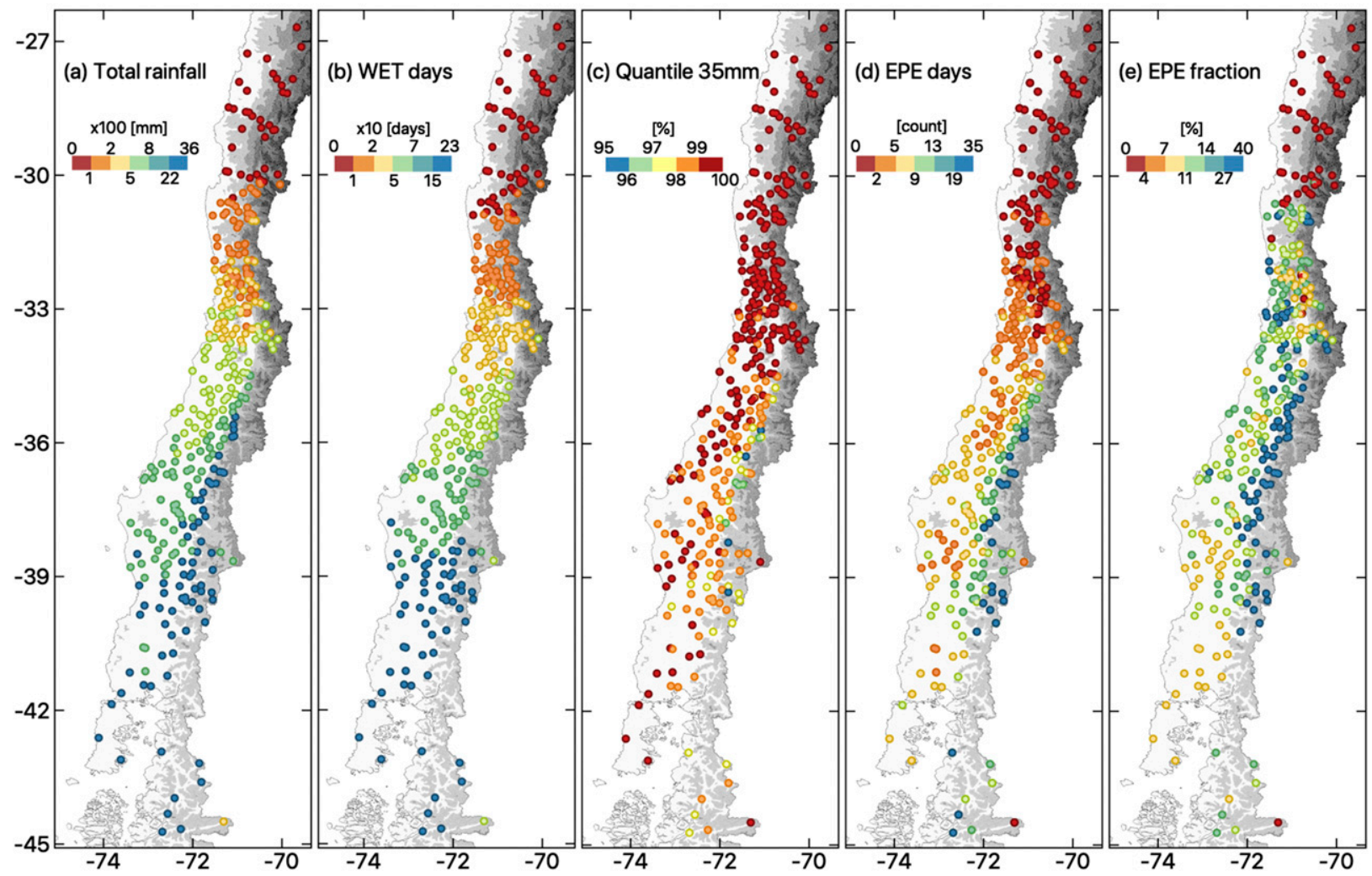

FIG. 2. Mean statistics for daily rainfall: (a) total annual rainfall, (b) number of wet days (rainfall $\geq 1 \mathrm{~mm}$ ), (c) quantile corresponding to $35 \mathrm{~mm}$, (d) number of EPEs (rainfall $\geq 35 \mathrm{~mm}$ ), and (e) fraction of EPEs relative to wet days. Stations have between 20 and 50 years or available data so statistics are derived as the average of a randomly selected 20 -yr series repeated 50 times.

the mean annual accumulated rainfall in central-southern Chile. There is an evident meridional gradient of rainfall, with annual accumulations exceeding $2000 \mathrm{~mm}$ toward $45^{\circ} \mathrm{S}$ but close to $100 \mathrm{~mm}$ toward $27^{\circ} \mathrm{S}$, displaying the strong influence of the midlatitude storm track on the annual accumulation. Along with the meridional gradient, there is a zonal gradient between $\sim 35^{\circ}$ and $38^{\circ} \mathrm{S}$, with $\sim 800 \mathrm{~mm}$ along the coast and $>2000 \mathrm{~mm}$ toward the Andes, in agreement with previous studies showing the strong orographic impact that the Andes has over the accumulated rainfall along its windward side (Barrett et al. 2009; Garreaud 2009; Viale and Garreaud 2015).

In addition to the mean annual accumulated rainfall, the mean frequency of daily rainfall provides more information about hydroclimatic characteristics. Figure $2 b$ displays the mean annual frequency of days with rainfall $\geq 1 \mathrm{~mm}$ (WET days). There is a southward increase of WET days, with $<20$ WET days between $26^{\circ}$ and $33^{\circ} \mathrm{S}$ and $>150$ WET days south of $\sim 38^{\circ} \mathrm{S}$. Unlike the annual rainfall accumulation, there is no apparent increase in frequency associated with the Andes Mountains; nevertheless, using hourly rainfall observations over a 16-month period, Viale and Garreaud (2015) determined a cross-barrier increase of rainfall intensity and frequency due to longer-lasting storms over the Andes associated with either an earlier onset or later dissipation.

\section{b. Overall spatial characteristics of extreme rainfall}

The study of extreme phenomena includes at least two approaches: 1) segregate observations by choosing the maximum value in a period of time, called block maxima (e.g., maximum per year) and 2) account all the observations equal and above a fixed threshold, called peaks over threshold (POT; Wilks 2011). We selected the POT methodology because it allows us to include a larger fraction of observations compared with block maxima.

A daily rainfall threshold of $35 \mathrm{~mm}$ (POT35) was selected to define extreme precipitation events (EPEs). This value was chosen after examining other thresholds and finding a compromise between the number of cases 
that could be retained and what is empirically considered an extreme daily rainfall in central-southern Chile. To highlight the natural hazard context, POT35 was contrasted with flooding events for Santiago and Concepción (two major urban areas) reported in the natural disaster inventory DesInventar (e.g., Marulanda et al. 2010). This inventory includes floods produced by rainfall between 1970 and 2010 and uses newspaper as sources, so normally a one day offset between the rainfall date and the news date (one day after) was detected. Each flooding date was checked against the daily rainfall observed in Quinta Normal and Carriel Sur stations for Santiago and Concepción, respectively. To have a more representative rainfall value for each flooding event, the average of the closest stations within $30 \mathrm{~km}$ (8-9 stations) was considered. Figure 3 indicates that POT35 captures the majority of flooding events produced by rainfall: 17 of 28 cases in Quinta Normal (61\%) and 16 of 24 cases in Carriel Sur (66\%). Therefore, POT35 is representative of extreme conditions in major urban areas.

A spatial quantification of the extreme character of POT35 was performed by mapping the corresponding quantile value of each station. Figure $2 \mathrm{c}$ indicates that POT35 is equivalent to select a percentile equal or larger to $98 \%$ for the majority of the stations. In other words, daily rainfall $\geq 35 \mathrm{~mm}$ corresponds to the top $2 \%$ of the rainfall events. Note that percentiles tend to approach $100 \%$ for stations north of $33^{\circ} \mathrm{S}$ because they are under drier climatology and thus their daily rainfall rarely surpass $35 \mathrm{~mm}$. Also, note that percentiles tend to decrease $(95 \%-97 \%$, equivalent to top $5 \%-3 \%$ ) toward the Andes south of $35^{\circ}$ S, likely associated with longer tails in the frequency distribution of rainfall for these stations (Panorska et al. 2007).

The mean annual frequency of EPEs for POT35 is presented in Fig. 2d. North of $35^{\circ} \mathrm{S}$, WET and EPE days patterns are similar, showing monotonically decreasing values (Fig. 2b); however, there is a striking difference between $35^{\circ}$ and $40^{\circ} \mathrm{S}$. While WET days monotonically increase southward, EPE days just slightly change in the meridional direction and increase significantly eastward, from 5-9 events in average per year along the coast to 19-35 events over the steeper terrain of the Andes. Apparently, this eastward increase of EPE days is absent between $40^{\circ}$ and $45^{\circ} \mathrm{S}$; however, there are fewer rain gauges over the steeper Andes terrain to confirm this pattern. Considering that the mean annual accumulated rainfall also increases toward the Andes between $35^{\circ}$ and $40^{\circ} \mathrm{S}$ (Fig. 2a), this result suggests an important orographic control, where extreme rainfall events along the Andes foothills contribute significantly to annual

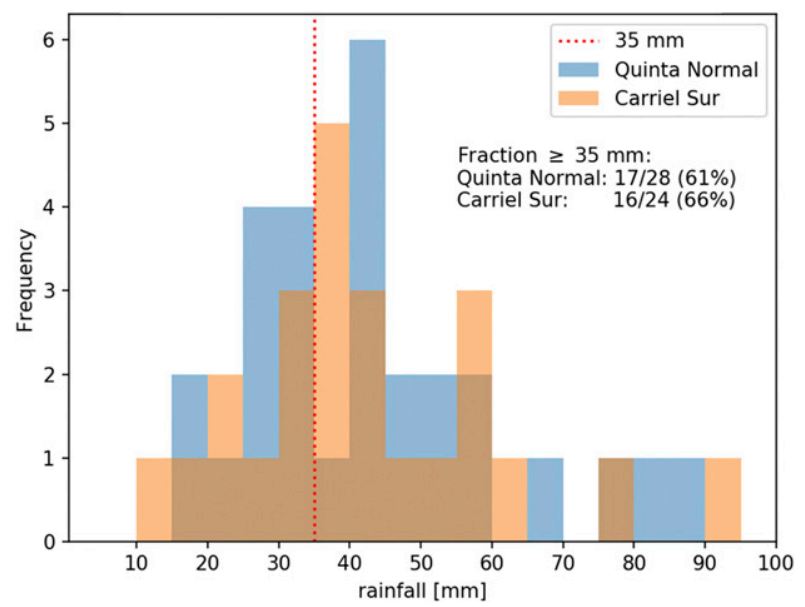

FIG. 3. Histogram of average daily rainfall during flooding events reported in the natural disaster inventory DesInventar. The average is calculated considering the nearest neighbor stations in a radius of $30 \mathrm{~km}$ relative to Carriel Sur and Quinta Normal (between 8 and 9 stations).

totals. Conversely, along the coast it is likely that the relatively high frequency of light rainfall events contributes to most of the annual totals.

The so defined EPEs can have a major impact in an area with low frequency of WET days (i.e., relatively dry climates) because ecosystems and population are not adapted to wet conditions. Therefore, the EPE frequency relative to WET days frequency can be more informative from a natural-hazard standpoint. A fraction $>27 \%$ of EPEs is concentrated in a contiguous and narrow area in the Andes foothills between $34^{\circ}$ and $41^{\circ} \mathrm{S}$ (Fig. 2e). In addition, there is a second area with fractions above $27 \%$ in the coastal range between $32^{\circ}$ and $33^{\circ} \mathrm{S}$. As a result, despite that between $30^{\circ}$ and $35^{\circ} \mathrm{S}$ we find a relatively dry zone, it concentrates a significant fraction of daily precipitation events $\geq 35 \mathrm{~mm}$, and therefore it can be considered as a hydroclimatic risk-prone area, especially coastward nearby $33^{\circ} \mathrm{S}$.

\section{c. Seasonality of EPEs}

Figure 4 shows the fraction of EPEs relative to WET days for each austral season. In average, less than $10 \%$ of EPEs are observed during summer (DecemberFebruary), mostly concentrated south of $36^{\circ} \mathrm{S}$, with some scattered stations showing fractions between $10 \%$ and $20 \%$ (Fig. 4a). Given the season, these events are most likely associated with convective rain, for example, in a frontal environment. Relative EPE fractions increase mostly between $20 \%$ and $40 \%$ south of $34^{\circ} \mathrm{S}$ during the fall (March-May), distributed more or less homogeneously over the domain 
Seasonality of mean annual EPEs ( $\geq 35 \mathrm{~mm})$
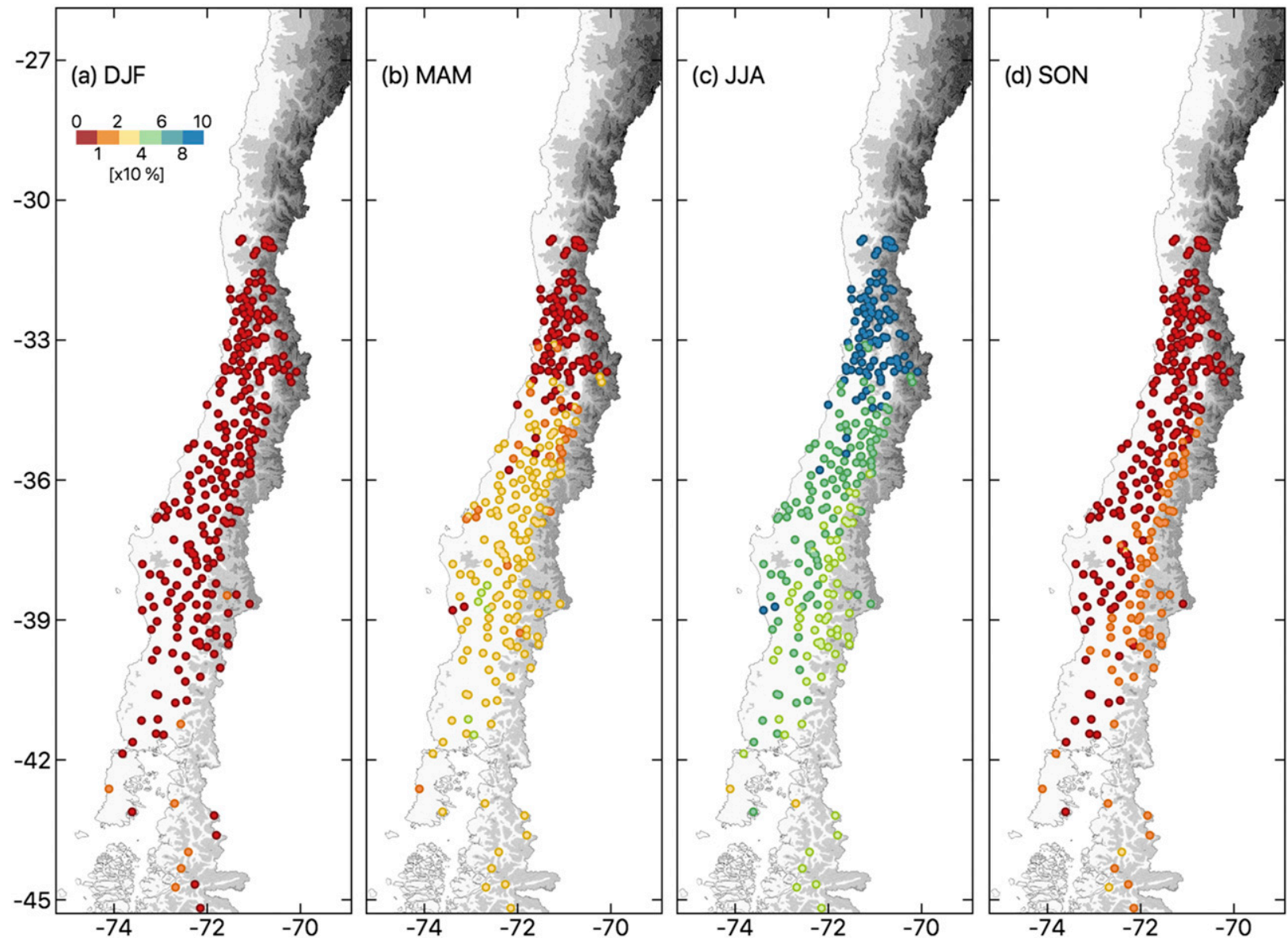

FIG. 4. Average fraction (\%) of EPEs per season: (a) December-February, (b) March-May, (c) June-August, and (d) September-November.

(Fig. 4b). Throughout the winter (June-August) the largest fraction of EPEs $(80 \%-100 \%)$ is observed between $31^{\circ}$ and $34^{\circ} \mathrm{S}$, a fraction that decreases southward monotonically up to $40 \%$ (Fig. 4c). By spring (September-November) EPEs decrease to 2-3 events in this area (Fig. 4d). Accordingly, these results indicate that the most likely season to have EPEs is winter north of $34^{\circ} \mathrm{S}$. South of $34^{\circ} \mathrm{S}$, EPEs are distributed between May and November with a peak in austral winter. Summer is the less likely season for extreme daily rainfall events.

\section{d. Duration and latitudinal impact of EPEs}

These two features are addressed by selecting four reference locations along the observation domain: $\mathrm{La}$ Serena (29.9 $\left.{ }^{\circ} \mathrm{S}\right)$, Quinta Normal $\left(33.4^{\circ} \mathrm{S}\right)$, Carriel Sur $\left(36.7^{\circ} \mathrm{S}\right)$, and Puerto Montt $\left(41.4^{\circ} \mathrm{S}\right)$. Each location is associated with important populated areas, especially Quinta Normal located in Chile's capital, Santiago, and
Carriel Sur located in the second most populated city, Concepción.

How long can an EPE last? To answer this, the number of continuous days with rainfall $\geq 35 \mathrm{~mm}$ was counted for each reference location. The majority of events last for only 1 day at each reference location. Events $\geq 35 \mathrm{~mm}$ lasting 2 days are rare (less than 3 between 1979 and 2017), except in Carriel Sur with 17 cases. Events equal or longer than 3 days are rare at all reference locations. One caveat of counting EPE duration from daily observations is that rainfall is accumulated in fixed time blocks, between 1200 and 1200 UTC of the following day. Therefore, EPEs accumulating $\geq 35 \mathrm{~mm}$ but crossing 1200 UTC can be divided into two days with $<35 \mathrm{~mm}$ and thus be counted as non-EPEs. To gain further insight about EPEs duration, hourly rainfall observations provided by Dirección General de Aguas from selected reference stations (Santiago, Concepción, Puerto Montt) 


\section{Median rainfall for EPE days ( $\geq 35 \mathrm{~mm}$ ) of reference stations}
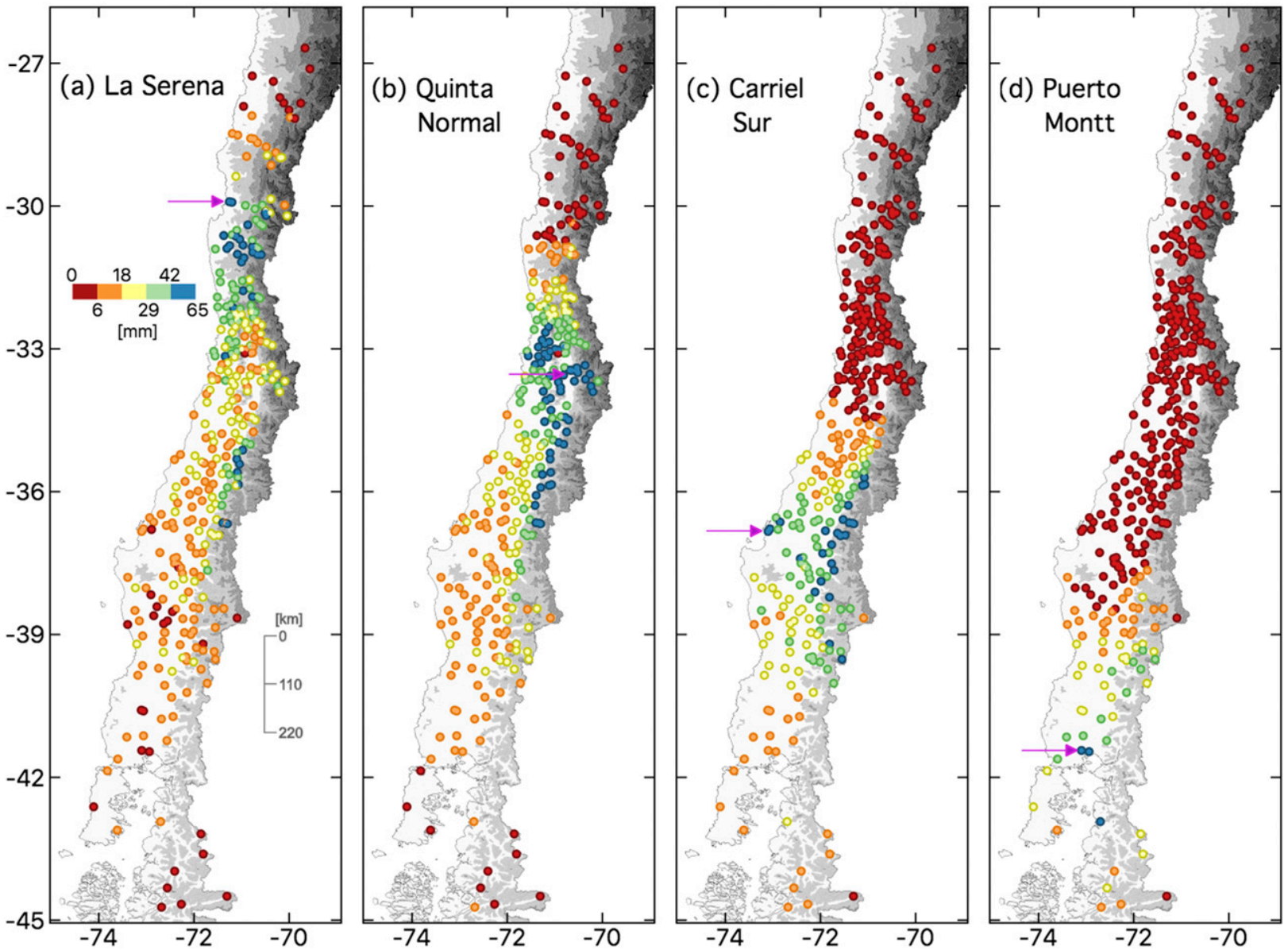

FIG. 5. Median rainfall for EPE dates corresponding to reference locations: (a) La Serena, (b) Quinta Normal, (c) Carriel Sur, and (d) Puerto Montt. The magenta arrow in each panel shows the location of the reference station.

were examined, indicating that EPEs tend to last in average between 21 and $25 \mathrm{~h}$, with long-lasting EPEs more frequently observed in Concepción (see the appendix and Table $\mathrm{S} 1$ in the online supplemental material).

Another driving question of this study is the latitudinal range of EPEs. For a given reference location, its set of EPE dates was retrieved and the median rainfall computed for the same dates of all the stations, including the reference location. Figure 5a reveals that when EPEs occur in La Serena, heavy rainfall (median rainfall of $42-65 \mathrm{~mm}$ ) also impacts a band of about $200 \mathrm{~km}$ to the south, both along the coast, interior valleys and the Andes slope. A second maximum is evident between $35^{\circ}$ and $36^{\circ} \mathrm{S}$ over the Andes foothills. The rainfall minimum $<18 \mathrm{~mm}$ around $33^{\circ} \mathrm{S}$ could be associated to a rain shadow effect because north of $32^{\circ} \mathrm{S}$ the steep terrain runs from coast to the Andes mountain and moisture flux proceed generally from the northwest at this latitude (see section 4). Relative to Quinta Normal (Fig. 5b), maximum median rainfall spans roughly $\sim 330 \mathrm{~km}$ and impacts the north and south asymmetrically. To the north, large rainfall extends less than $100 \mathrm{~km}$, but they are observed from the coast to the Andes foothills. To the south, there is a longer band of large precipitation but it is concentrated over the Andes foothills. Relative to Carriel Sur (Fig. 5c), maximum median rainfall spans about $220 \mathrm{~km}$ and it is concentrated again toward the Andes foothills, with some heavy rainfall along the coast nearby the reference station. Finally, considering Puerto Montt (Fig. 5d), maximum median rainfall decays rapidly northward to 29-42 mm. Apparently the spanning area of maximum median rainfall covers $\sim 150 \mathrm{~km}$, but the limited number of rain gauges makes difficult to assert this with precision. To overcome the limited surface observations over the Andes Mountains, the same analysis was repeated with CR2MET daily precipitation product using the EPE days 
for each reference station (see Fig. S1). Along with a good agreement where surface stations exist, results indicate that heavy rainfall is not only present along the Andes foothills but also that median precipitation could even exceed $65 \mathrm{~mm}$ over the Andes, especially in Quinta Normal cases. In addition, heavy rainfall associated with Puerto Montt shows a band of maximum median rainfall spanning about $220 \mathrm{~km}$ over the Andes, in agreement with the rest of the reference stations. Overall, the maps in Fig. 5 emphasize the crucial role of the Andes in shaping the region affected by heavy rainfall.

To generalize the results presented previously, a similar analysis was repeated but now for each available surface station, obtaining the northern and southernmost latitude that exceeded a given rainfall threshold. A latitudinal $0.5^{\circ}$ moving average was applied to remove noise and capture the general pattern of the rainfall impact (Fig. 6). It is evident that extreme rainfall tends to concentrate in narrow latitudinal bands. For instance, for a 35-mm threshold, the north-south width of the heavy rainfall is about $200 \mathrm{~km}$, but such width nearly doubles if considering a $20-\mathrm{mm}$ threshold. At northern locations (e.g., La Serena and Quinta Normal) heavy rainfall tends to encompass mostly a band to the south of the reference station. Farther to the south (e.g., Carriel Sur, Puerto Montt), the spreading of the heavy rainfall area tends to be more symmetric and is always large close to the Andes foothills. This variation could be related with the landfalling latitude and onshore moisture flux of the storms. For instance, storms impacting Puerto Montt, located closer to the storm track, could be associated with relatively low amplitude troughs that produce significant eastward component of moisture flux. Consequently, the moisture can spread evenly south and north of the landfalling latitude once impacting the Andes Mountains. As storms make landfall farther north (e.g., La Serena and Quinta Normal), higher amplitude troughs are necessary to produce rainfall. Consequently, the moisture flux impacting the Andes would have a significant southward component, spreading rainfall in this direction.

\section{Empirical relationship between EPEs and moisture fluxes}

The relationship between upslope moisture fluxes and rainfall observed in complex terrain has proven to be a key aspect of orographic precipitation. For instance, by using a wind profiling radar and rain gauges at three representative locations along the coast of northern California, Neiman et al. (2002) demonstrated that a linear relationship between the upslope flow and rainfall in the coastal range explained about

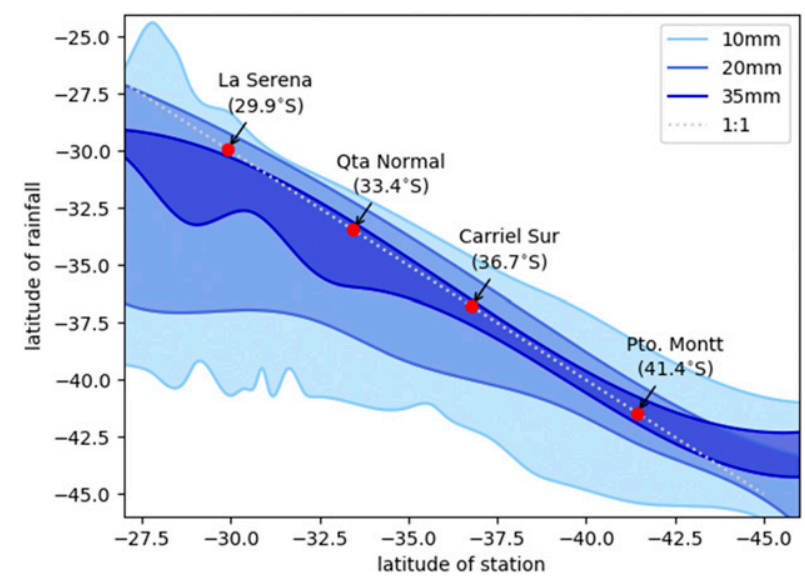

FIG. 6. Latitudinal extent of rainfall for different rainfall thresholds and for each rain gauge in the observation domain (shaded areas). Latitude of reference locations (red dots) and 1:1 line (white dashed) are included.

$94 \%$ of the variation in individual cases and up to $70 \%$ in a composited winter season. Other studies in the same area (e.g., Neiman et al. 2009) have reported similar association between upslope horizontal moisture flux and rainfall. In Chile, two of the few experiences in this regard are the studies by Garreaud et al. (2013, focused on Patagonia) and Falvey and Garreaud (2007, focused on central Chile). In the latter study, they employed daily rainfall observations from 10 winter seasons and 88 rain gauges in central Chile (between $32^{\circ}$ and $35^{\circ} \mathrm{S}$ ), along with balloon soundings from a single coastal radiosonde station located at $33.6^{\circ} \mathrm{S}$. The study found that the westerly moisture flux component produced the best fit with daily rainfall, explaining up to $60 \%$ of the rainfall variation, with an average value of $40 \%$. In this section we evaluate upstream air mass features using CFSR and explore its linear relationship with central-southern Chile WET and EPE days. Thus, we expand the results of Falvey and Garreaud (2007) by studying the linear relationship over a larger domain using reanalysis products and by including EPEs.

A multilinear regression is employed to examine the empirical relationship between moisture fluxes and rainfall. Instead of using a single radiosonde station (Falvey and Garreaud 2007), CFSR-derived IVT components sampled along the coast are employed in each rain gauge regression. The CFSR grid point employed is the nearest in latitude to the regressed rain gauge station (Fig. 1). A multilinear expression of the form $P=a \mathrm{IVT}_{u}+b \mathrm{IVT}_{v}+c$ was applied, where $P$ is the daily rainfall; $a, b, c$ are constants determined by a least squares method, and $\mathrm{IVT}_{u}$ and $\mathrm{IVT}_{v}$ are the zonal and meridional components of 
Multi-lineal regression analysis between daily IVT components and rainfall
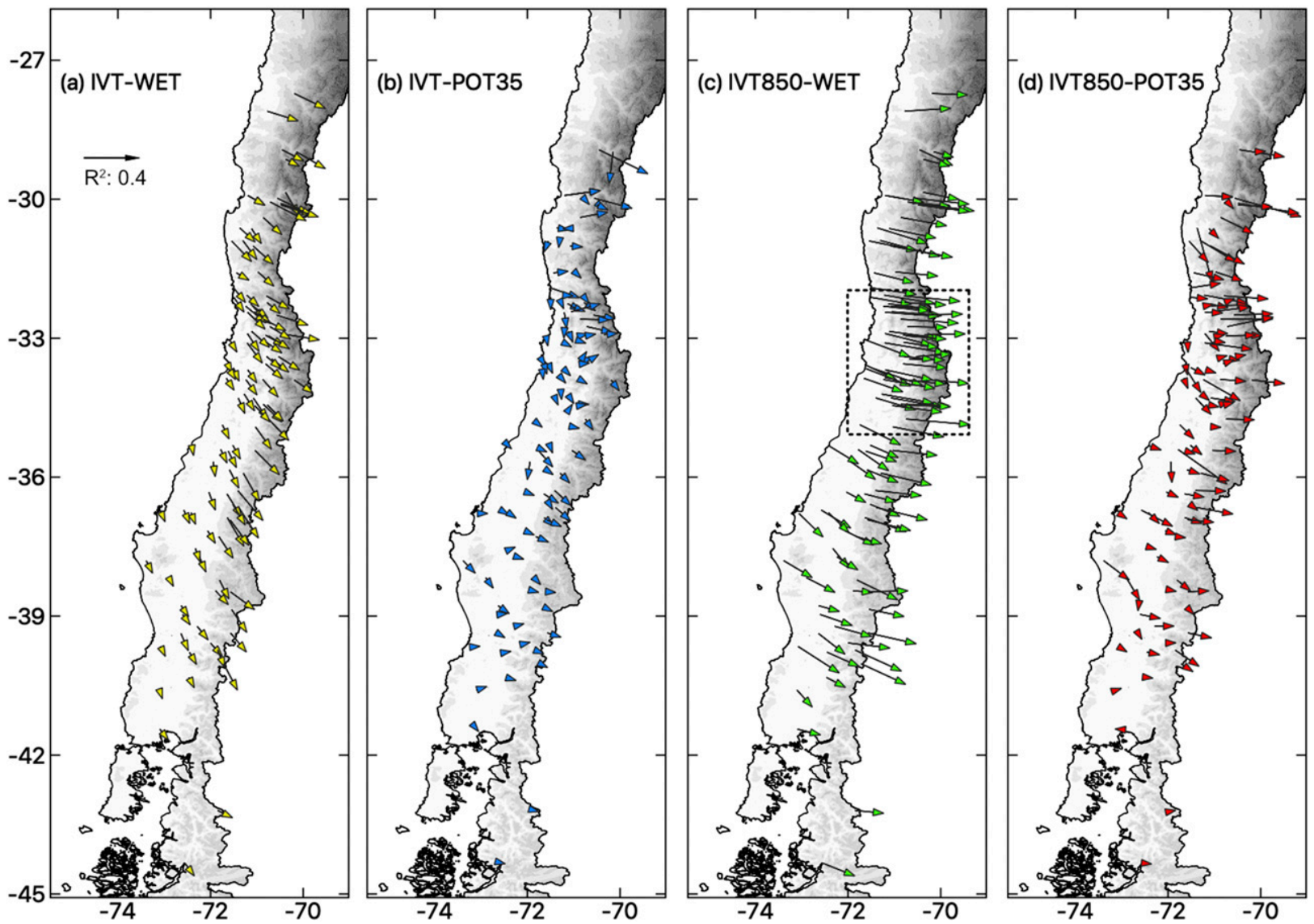

FIG. 7. Multilinear regression analysis between maximum daily IVT components and rainfall at individual rain gauges: (a) IVT components and days with rainfall $\geq 1 \mathrm{~mm}$ (WET), (b) IVT components and days with rainfall $\geq 35 \mathrm{~mm}$ (POT35), (c) IVT in a 50-hPa layer centered at $850 \mathrm{hPa}$ (IVT850), and (d) IVT850 and POT35. The length of the arrows is proportional to the coefficient of determination $R^{2}$ [key included in (a)], while the orientation is proportional to the weight of the component that produced the best fit. The dashed square in (c) indicates the domain of the Falvey and Garreaud (2007) study. One out of three stations is deployed to improve visualization.

maximum daily IVT, respectively. The multilinear coefficient of determination $\left(R^{2}\right)$ and the function arctangent $(a, b)$ were projected as vector length and direction, respectively. The predictors and predictands used in the analysis are 1) IVT and WET days, 2) IVT and POT35, 3) IVT in a 50-hPa-deep layer centered at $850-\mathrm{hPa}$ (IVT850) and WET days (similar to Fig. 9 in Falvey and Garreaud 2007), and 4) IVT850 and POT35.

The IVT-WET regression (Fig. 7a) indicates that variations in WET days are best explained by moist flux coming from the west and north in roughly the same proportion (i.e., vector pointing to southeast), with a maximum $R^{2}$ of $\sim 30 \%$. In addition, slightly higher correlation values are associated with elevated terrain. When selecting the relationship IVT-POT35 (Fig. 7b) $R^{2}$ values decay significantly to slightly above or below $10 \%$. Although the westerly component influence is still apparent, directions show more spread and no relationship with topography is apparent. This degraded relationship could be the result of a smaller sample influenced by mesoscale factors and therefore showing larger dispersion. The IVT850-WET relationship on the other hand (Fig. 7c), highlights the influence of the westerly moist flux in explaining variations of daily rainfall. The result is consistent with Falvey and Garreaud (2007) and shows that the strong relationship between the westerly component variation and rainfall extends mostly along all the central-southern Chile domain, explaining up to $\sim 40 \%$ of the daily rainfall variation. Again, when selecting the relationship between IVT850 and POT35 cases (Fig. 7d) there is an overall decrease in the coefficient of determination; however, the IVT850 variation is able to explain up to $\sim 40 \%$ of the extreme rainfall variation in some places, improving the relation relative to the deeper-integrated IVT field. 

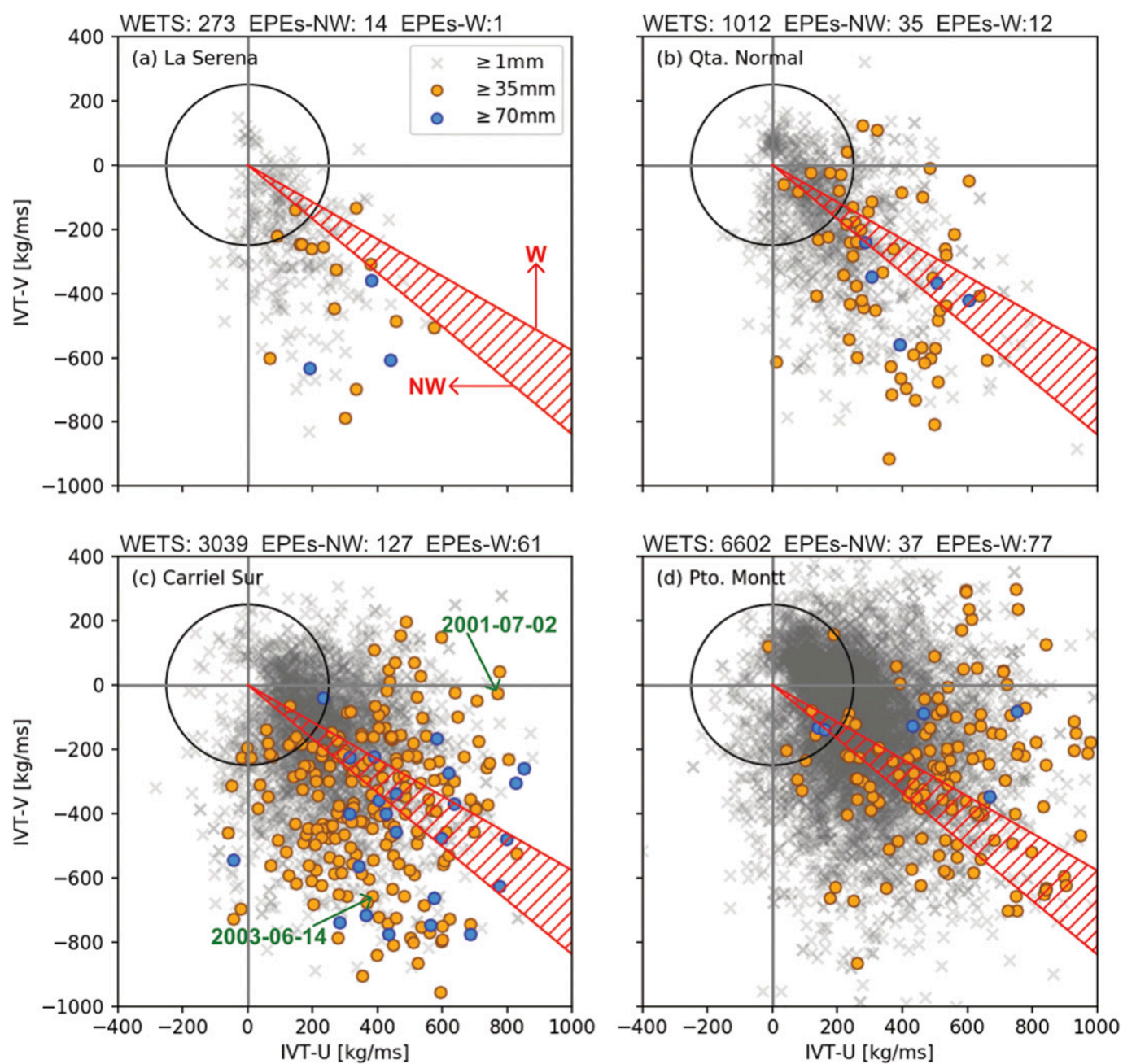

FIG. 8. Distribution of WET (gray crosses) and EPE days (filled circles) according to their CFSR-derived maximum daily IVT component between 1979 and 2017 for four reference locations: (a) La Serena, (b) Quinta Normal, (c) Carriel Sur, and (d) Puerto Montt. EPEs are subdivided into two groups with strong IVT from the westerly (W) and northwesterly (NW) direction. Each group is separated by a $120^{\circ}-130^{\circ}$ azimuth (red hatched area). EPEs $\geq 35 \mathrm{~mm}$ are highlighted in orange and $\geq 70 \mathrm{~mm}$ (twice the magnitude) in blue. IVT is derived from a $1.5^{\circ} \times 1.5^{\circ}$ latitude-longitude box located offshore in front of the reference location (Fig. 1). The black circle centered at the origin indicates an IVT limit of $250 \mathrm{~kg} \mathrm{~m}^{-1} \mathrm{~s}^{-1}$, one of the thresholds used in the literature to identify atmospheric rivers (e.g., Shields et al. 2018). The sample size of each group is included on the top of each panel. The dates of two cases studies, presented in Fig. 9, are included in (c).

Despite the linear relationships observed in this study are consistent with Falvey and Garreaud (2007) results, the fraction explained by these relationships are relatively poor compared with results of Neiman et al. (2002, 2009), especially considering the major role of orography in EPEs, as showed in Figs. 2 and 5. One reason for the degraded relationships could be the time scale employed in the analysis. Neiman et al. $(2002,2009)$ used hourly time steps of rainfall and water vapor flux, while Falvey and Garreaud (2007) and in this study the relationship is studied at daily level, which can introduce a larger temporal mismatch between the moist flux and its associated rainfall.

To gain further insights about the relationship between IVT components, WETs, and EPEs, the analysis is now focused on the four reference stations. For each of the four reference locations, we use the maximum daily IVT component averaged in an offshore $1.5^{\circ} \times$ $1.5^{\circ}$ latitude-longitude box at the same latitude of the reference station (Fig. 1). Figure 8 shows the distribution of the zonal and meridional IVT components for all WET days. La Serena and Quinta Normal have less 
TABLE 1. Mean IVT magnitude and standard deviation for WET and EPE groups of each location.

\begin{tabular}{llcc}
\hline \hline & Group & $\begin{array}{c}\text { IVT magnitude } \\
\text { and std dev }\end{array}$ & $\begin{array}{c}\text { Ratio } \\
\text { (EPE/WET) }\end{array}$ \\
\hline La Serena & WET & $292 \pm 170$ & \\
Quinta Normal & EPE & $505 \pm 204$ & 1.73 \\
& WET & $308 \pm 197$ & \\
Carriel Sur & EPE & $520 \pm 224$ & 1.69 \\
& WET & $361 \pm 188$ & \\
Puerto Montt & EPE & $589 \pm 209$ & 1.63 \\
& WET & $368 \pm 195$ & \\
& EPE & $635 \pm 222$ & 1.73 \\
\hline
\end{tabular}

WET days and less dispersion in the IVT space relative to Carriel Sur and Puerto Montt. In addition, WET days in the former locations are associated more frequently with northwesterly moist fluxes, while the two stations in the south display a wide range of WET days with westerly component. In all these locations there are some southwesterly and easterly flow cases, probably in connection with orographic blocking, as the terraintrapped-airflow cases presented in Valenzuela and Kingsmill (2015, 2018), cutoff lows (Garreaud and Fuenzalida 2007), or convection triggered in a postfrontal environment (Kirshbaum et al. 2018). These types of cases will not be examined in the present study. Similar to WETs, EPEs (orange and blue dots in Fig. 8) tend to spread all over the IVT space but most of them with IVT $>250 \mathrm{~kg} \mathrm{~m}^{-1} \mathrm{~s}^{-1}$, one of the thresholds employed to identify ARs (e.g., Shields et al. 2018). Despite some overlapping between EPEs and WETs distributions, moisture fluxes are in average larger during EPEs. For instance, Table 1 indicates that in average EPE cases tend to show between $63 \%$ and $73 \%$ larger IVT magnitudes compared with WET cases. Interestingly, even when doubling the rainfall threshold (e.g., $\geq 70 \mathrm{~mm}$, blue dots in Fig. 8), EPEs are widespread in the IVT domain. As EPEs can be observed either with relatively large and low moistures fluxes, this result implies the potential role of instabilities, along with forced orographic ascent, as forcing mechanisms of extreme rainfall. Therefore, in addition to the difference in the time-scale analysis, this could also explain the degraded linear relationship between moisture flux and rainfall found in both Falvey and Garreaud (2007) and the present study relative to Neiman et al. (2002, 2009).

\section{Mean synoptic conditions associated with EPEs}

A cursory inspection of Fig. 8 indicates that most EPEs exhibit a northwesterly (NW) IVT vector but some cases (especially in Carriel Sur and Puerto Montt) have a dominant westerly (W) IVT vector. Although this division may appear arbitrary, it is supported by the results of previous studies. For instance, Garreaud (2013) showed that warm storms in central Chile (Quinta Normal) featured strong zonal flow aloft while the majority of the cold storms featured northwesterly flow aloft. To complement those findings, let us consider two EPEs in Carriel Sur with almost the same IVT magnitude $\left(\sim 770 \mathrm{~kg} \mathrm{~m}^{-1} \mathrm{~s}^{-1}\right)$ identified in Fig. 8. Their attending synoptic conditions are shown in Fig. 9 and differ in important ways. The NW-IVT storm (Figs. 9a,c) features a deep trough with axis at $\sim 82^{\circ} \mathrm{W}$ and extending all the way to the surface near Carriel Sur, a jet streak in the trough's exit region at $32^{\circ} \mathrm{S}$, cyclonic winds offshore near the surface $(850 \mathrm{hPa})$, and a long corridor of integrated moisture $(\geq 30 \mathrm{~mm})$ reaching Carriel Sur with a southeast-northwest orientation. In contrast, the W-IVT storm (Figs. 9b,d) features an upper-level ridge and trough in the northsouth direction over the Pacific with concomitant surface anticyclone $\left(30^{\circ} \mathrm{S}, 90^{\circ} \mathrm{W}\right)$ and cyclone $\left(54^{\circ} \mathrm{S}, 84^{\circ} \mathrm{W}\right)$, and zonally oriented features in the jet streak, near surface winds, and integrated moisture over the Pacific.

To provide a broader view of these features, the set of EPEs belonging to each reference station and IVT group ( $\mathrm{NW}$ and $\mathrm{W}$ ) were composited in averages of selected synoptic variables. Table 2 summarizes the main features of each group in the four reference stations. The number of NW cases is always larger than the $\mathrm{W}$ cases except for Puerto Montt. The ratio of NW to $\mathrm{W}$ cases is $14,3,2$, and 0.5 in La Serena, Quinta Normal, Carriel Sur, and Puerto Montt, respectively. There are no significant differences in the mean and median rainfall between NW and W groups. Nevertheless, the fraction of cases with rainfall $>50 \mathrm{~mm}$ is slightly larger for the NW group. When considering rainfall days $>70 \mathrm{~mm}$, there is a transition between larger frequencies in $\mathrm{W}$ cases in the south (e.g., Puerto Montt) to NW in the north (La Serena).

Strong water vapor fluxes can be produced by the socalled ARs. However, another source can be cutoff lows showing strong water vapor flux convergence (e.g., Singleton and Reason 2007; Bozkurt et al. 2016). Therefore, it is important to quantify how frequent strong IVT cases at single stations are linked to ARs. The study of Viale et al. (2018) produced a catalog with ARs identified in each 6-h CFSR step between 2001 and 2016 that was updated to 1979-2017 for the purposes of the present study. An AR was identified in an EPE day (containing five 6-h CFSR steps, section 2) if at least one 6-h step is identified as AR. It can be seen in Table 2 that the NW group possess a larger frequency of ARs relative to the $\mathrm{W}$ group. However, 

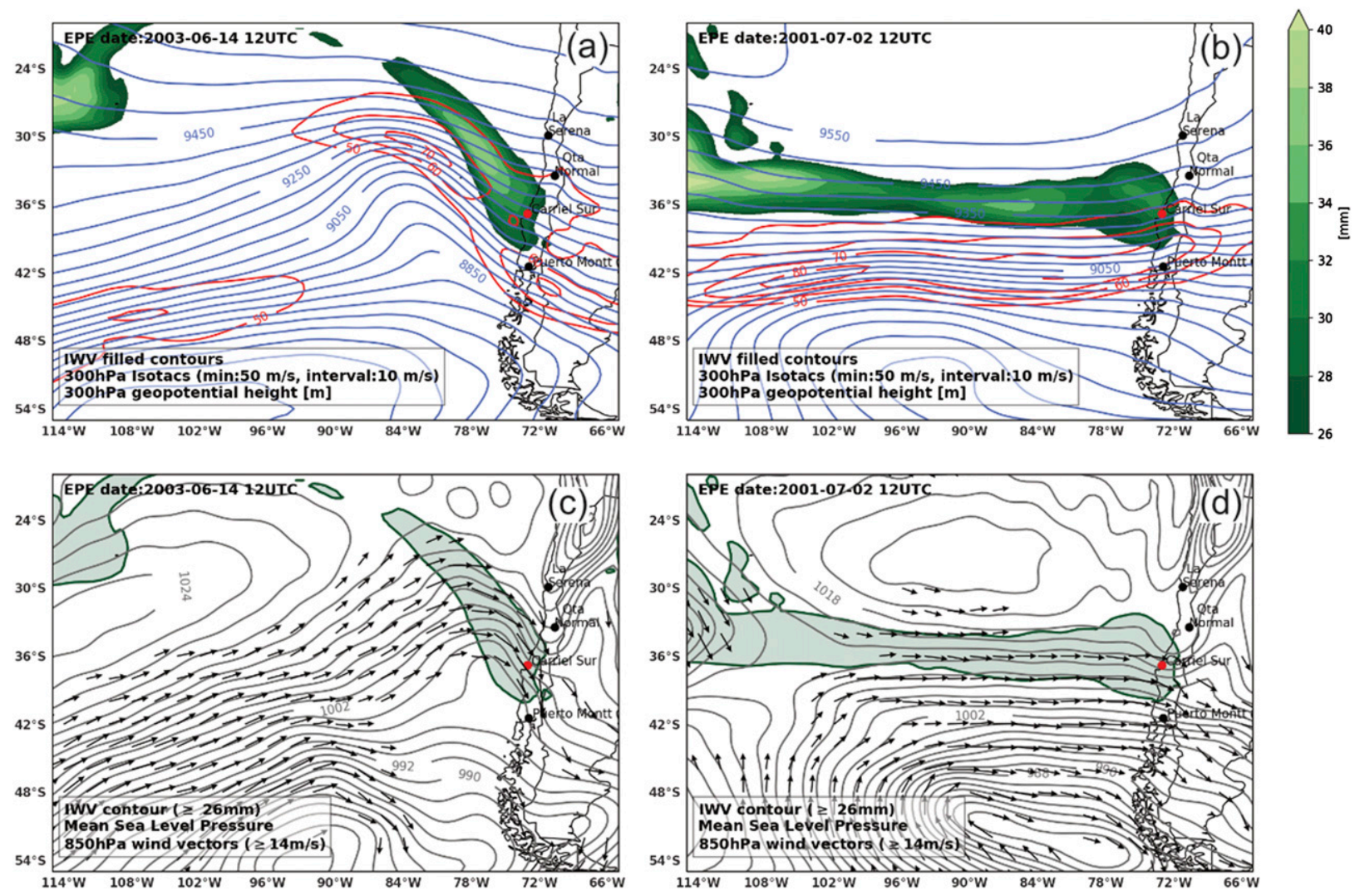

FIG. 9. CFSR analyses for two case studies of extreme rainfall observed at Carriel Sur with strong IVT from (a),(c) NW and (b),(d) W groups. Each case is associated with an IVT magnitude of $\sim 770 \mathrm{~kg} \mathrm{~m}^{-1} \mathrm{~s}^{-1}$. Fields included are IWV (filled contour), sea level pressure (gray contour), and $850-\mathrm{hPa}$ wind vectors $\geq 14 \mathrm{~m} \mathrm{~s}^{-1}$ in (a) and (b), and IWV $\geq 26 \mathrm{~mm}$ (hatched), 300-hPa isotacs (red contours), and 300-hPa geopotential height (blue contours) in (c) and (d).

an inspection of IWV and IVT components of each EPE day (not shown) suggest no significant difference between NW and $\mathrm{W}$ groups that could explain the differences in the AR fractions found. One hypothesis is that the NW and $\mathrm{W}$ difference in AR frequency could be an artifact of the Viale et al. (2018) algorithm itself, owing to it was required an IVT direction coming from the $270^{\circ}-360^{\circ}$ sector to detect an AR (among other criteria). In this way, IVT fields in the W group might have the chance to proceed from a direction slightly lower than $270^{\circ}$ and thus be classified as non-AR. When considering ARs regardless of their NW and W group (Table 2), it is clear that ARs contribute to EPE rainfall more often toward the southern part of the domain, where they are responsible for more than half of EPE cases in Carriel Sur and

TABLE 2. EPEs, ARs, and rainfall statistics for each reference station and IVT group (W, NW) presented in Fig. 8. Included are number of EPEs, mean and median rainfall $(\mathrm{mm})$ of the EPE group, number and percentage of events in the tail above $50 \mathrm{~mm}$ and above $70 \mathrm{~mm}$, and number and percentage of ARs identified with the method of Viale et al. (2018).

\begin{tabular}{|c|c|c|c|c|c|c|c|c|c|}
\hline & IVT group & $\begin{array}{l}\text { EPEs } \\
\text { (count) }\end{array}$ & $\begin{array}{l}\text { Mean } \\
(\mathrm{mm})\end{array}$ & $\begin{array}{l}\text { Median } \\
(\mathrm{mm})\end{array}$ & $\begin{array}{c}>50 \mathrm{~mm} \\
\text { (count, \%) }\end{array}$ & $\begin{array}{c}>70 \mathrm{~mm} \\
(\text { count, } \%)\end{array}$ & $\begin{array}{c}\mathrm{AR} \\
\text { (count, \%) }\end{array}$ & $\begin{array}{c}\text { Total EPEs } \\
(\text { count } \mathrm{NW}+\mathrm{W})\end{array}$ & Total AR \\
\hline \multirow[t]{2}{*}{ La Serena } & NW & 14 & 55.5 & 48.8 & $7(50 \%)$ & $3(21 \%)$ & $4(29 \%)$ & 15 & $4(27 \%)$ \\
\hline & $\mathrm{W}$ & 1 & 46.2 & 46.2 & 0 & 0 & - & & \\
\hline \multirow[t]{2}{*}{ Quinta Normal } & NW & 35 & 52.3 & 50.9 & $19(54 \%)$ & $2(6 \%)$ & $12(34 \%)$ & 47 & $16(34 \%)$ \\
\hline & $\mathrm{W}$ & 12 & 46.0 & 42.0 & $4(33 \%)$ & 0 & $4(33 \%)$ & & \\
\hline \multirow[t]{2}{*}{ Carriel Sur } & NW & 127 & 50.5 & 44.9 & $49(39 \%)$ & $11(9 \%)$ & $71(56 \%)$ & 188 & $101(54 \%)$ \\
\hline & $\mathrm{W}$ & 61 & 49.7 & 43.4 & $19(31 \%)$ & $5(8 \%)$ & $30(49 \%)$ & & \\
\hline \multirow[t]{2}{*}{ Puerto Montt } & NW & 37 & 45.9 & 41.7 & $12(32 \%)$ & 0 & $27(73 \%)$ & 114 & $75(66 \%)$ \\
\hline & $\mathrm{W}$ & 77 & 46.2 & 43.3 & $19(25 \%)$ & $4(5 \%)$ & $48(62 \%)$ & & \\
\hline
\end{tabular}


Puerto Montt, result that is consistent with Viale et al. (2018). In addition, in the northern part of the domain, the fraction of EPEs not associated with ARs could be linked to cutoff lows, where the climatology indicates a high frequency of occurrence (Fuenzalida et al. 2005).

The composite synoptic analysis of each group included mean fields of CFSR-derived IWV, 300-hPa geopotential height and isotachs, mean sea level pressure, and mean $850-\mathrm{hPa}$ wind vectors for EPE days of each reference location (Figs. 10 and 11). The composite of NW cases shows a 300-hPa geopotential height with a well-defined ridge-trough pattern in the zonal direction, with the trough's axis close to the coast (Figs. 10a,c,e,g). The upper-level wave is more marked in the midlatitudes, but it projects into subtropical latitudes. Note that the trough's amplitude is large when considering La Serena (northernmost reference station) but decreases when considering stations farther south. Under these conditions (and consistent with the group's definition) northwesterly (geostrophic) wind occurs near the reference station at the exit side of an upper-level jet streak. The jet streak over the southeast Pacific is strong when considering La Serena $\left(>50 \mathrm{~m} \mathrm{~s}^{-1}\right)$ but much weaker when considering Puerto Montt. A northwest-southeast oriented band of high IWV $(>30 \mathrm{~mm})$ with its axis reaching the coast near the latitude of the reference station is evident in the four NW composites. However, in the cases of La Serena and Quinta Normal, the IWV band is concentrated closer to the coast, while for Carriel Sur and Puerto Montt it extends into the middle of the Pacific. This suggests that, under NW-IVT, high precipitation events require, on average, strong synoptic forcing when considering stations in northern Chile to compensate relatively low moisture values. In contrast, EPEs in stations farther south can occur with a weaker (or more variable) synoptic forcing but they are accompanied by larger amounts of moisture. The caveat here is that averaging a larger sample of EPE cases in the southern reference stations could be smoothing out strong synoptic features (e.g., large amplitude troughs) that vary in space.

While some differences in the NW composites occurs when considering different references stations, the most salient differences occur when considering EPEs in the W-IVT group (Figs. 10b,d,f,h). In this case, the mean synoptic pattern is quite similar among the reference stations. The $300-\mathrm{hPa}$ geopotential height over the southeast Pacific shows a weak trough at midlatitudes and an even weaker ridge in the subtropics. This configuration leads to strong, mostly zonal upper-level flow at the latitude of the reference station with jet streaks exceeding $50 \mathrm{~m} \mathrm{~s}^{-1}$. The zonal flow is also observed together with a zonally oriented band of high IWV reaching the coast at the reference latitude with values exceeding $30 \mathrm{~mm}$.

The mean sea level pressure of composite NW cases features a surface depression over the Pacific between the coast and $84^{\circ} \mathrm{W}$ (Figs. 11a,c,e,g). The cyclonic circulation close to the coast force northwesterly winds near the surface $(850 \mathrm{hPa})$ within the area of IWV $\geq 30 \mathrm{~mm}$. On the other hand, composites of $\mathrm{W}$ cases show a broad surface anticyclone dominating the southeastern Pacific and a weak trough close to the coast and well to the south (Figs. 11b,d,f,h). As such, winds tend to be southwesterly over the Pacific and turn cyclonically near the coast, producing westerly moist flux along the coast. Additional evidence for the differences in NW and $\mathrm{W}$ synoptic forcing is provided by vertical velocity associated with each reference location (Fig. 12). Results show that vertical velocity in NW and $\mathrm{W}$ cases is more distinguishable from WETs in Carriel Sur and Puerto Montt than La Serena and Quinta Normal, with NW cases presenting larger average vertical velocities compared with $\mathrm{W}$ cases. In addition, there is monotonically increasing magnitude of the vertical velocity northward, with an average NW vertical velocity of La Serena that doubles the corresponding value of Puerto Montt, while in the $\mathrm{W}$ cases the difference is about $60 \%$ (acknowledging that La Serena has only one day composite). Therefore, despite a continuum variation between IVT direction and EPEs (Fig. 8), the upper and surface synoptic conditions described here support the differentiation of two discrete modes of rainfall forcing: NW cases, where there is a strong large-scale synoptic forcing that is accentuated for landfalling storms closer to $30^{\circ} \mathrm{S}$, and $\mathrm{W}$ cases, where the largescale synoptic forcing is relatively weaker (not too different from ordinary WET days) and the underlying terrain tends to dominate the forcing of EPEs.

An inspection of the mean vertical profiles for Quinta Normal and Carriel Sur provides further evidence for the forcing mechanism. NW cases are colder and drier than $\mathrm{W}$ cases, except within the first kilometer where these features either reverse or are similar (Figs. 13a,b,e,f). NW cases also tend to present more negative values of Brunt-Väisälä frequency below $1 \mathrm{~km}$ and therefore be more unstable in this layer, especially the cases observed in Quinta Normal (Figs. 13c,g). Finally, NW cases tend to show stronger northerly winds close to the surface that become northwesterly from $1 \mathrm{~km}$ upward, while $\mathrm{W}$ cases show relatively weak northwesterly winds near the surface that become stronger and westerly from $1 \mathrm{~km}$ upward (Figs. 13d,h). Stronger northerly winds in the NW 

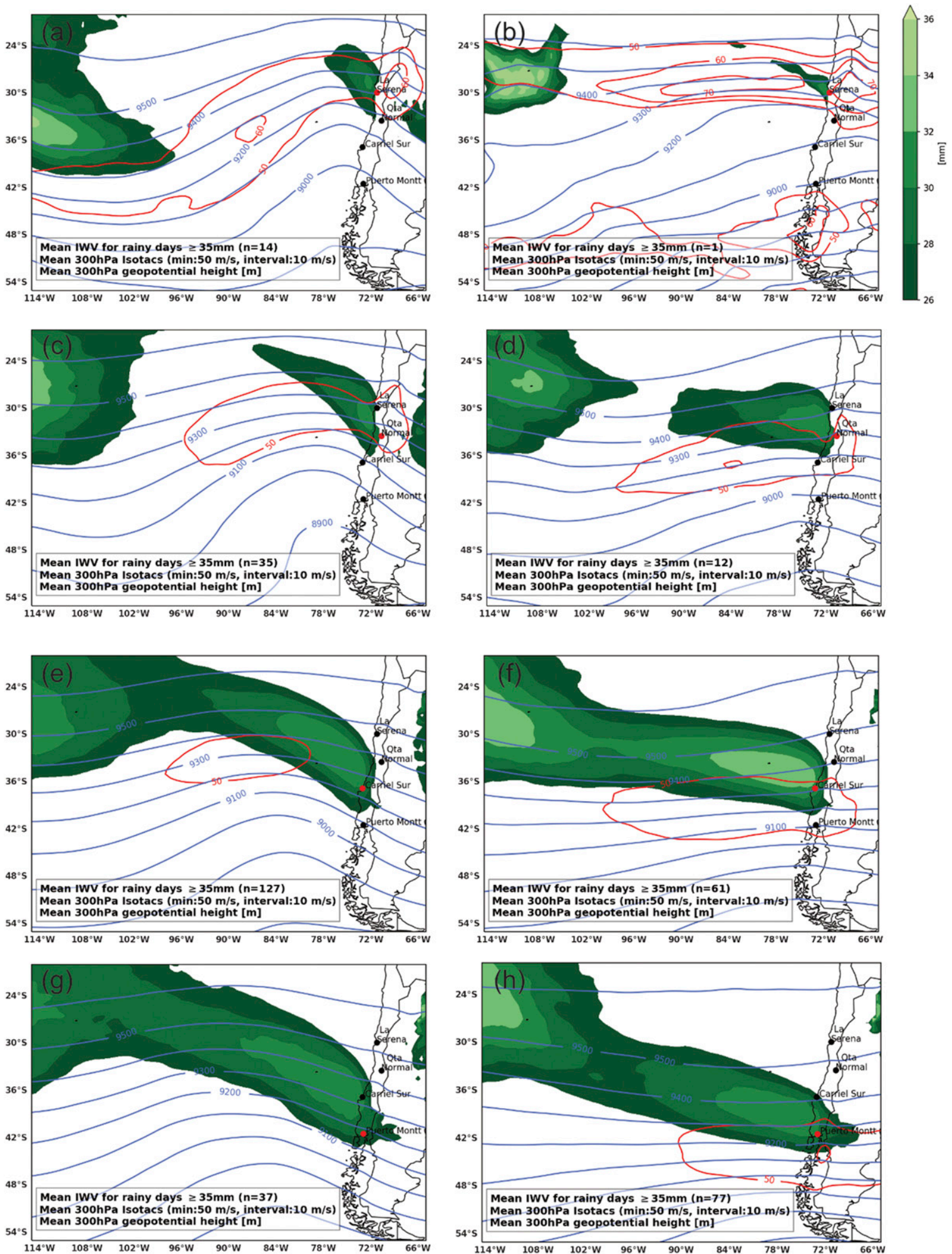

FIG. 10. CFSR-derived mean composites for POT35 associated to each reference location: (a),(b) La Serena; (c),(d) Quinta Normal; (e),(f) Carriel Sur; and (g),(h) Puerto Montt and IVT group: (left) NW and (right) W. Included fields are IWV $\geq 26 \mathrm{~mm}$ (filled contours), 300-hPa geopotential height ( $\mathrm{m}$; blue contours), and 300-hPa isotachs $\left(\mathrm{m} \mathrm{s}^{-1}\right.$; red contours). Note that (b) includes one event only (i.e., one day), and it is included for consistency. 

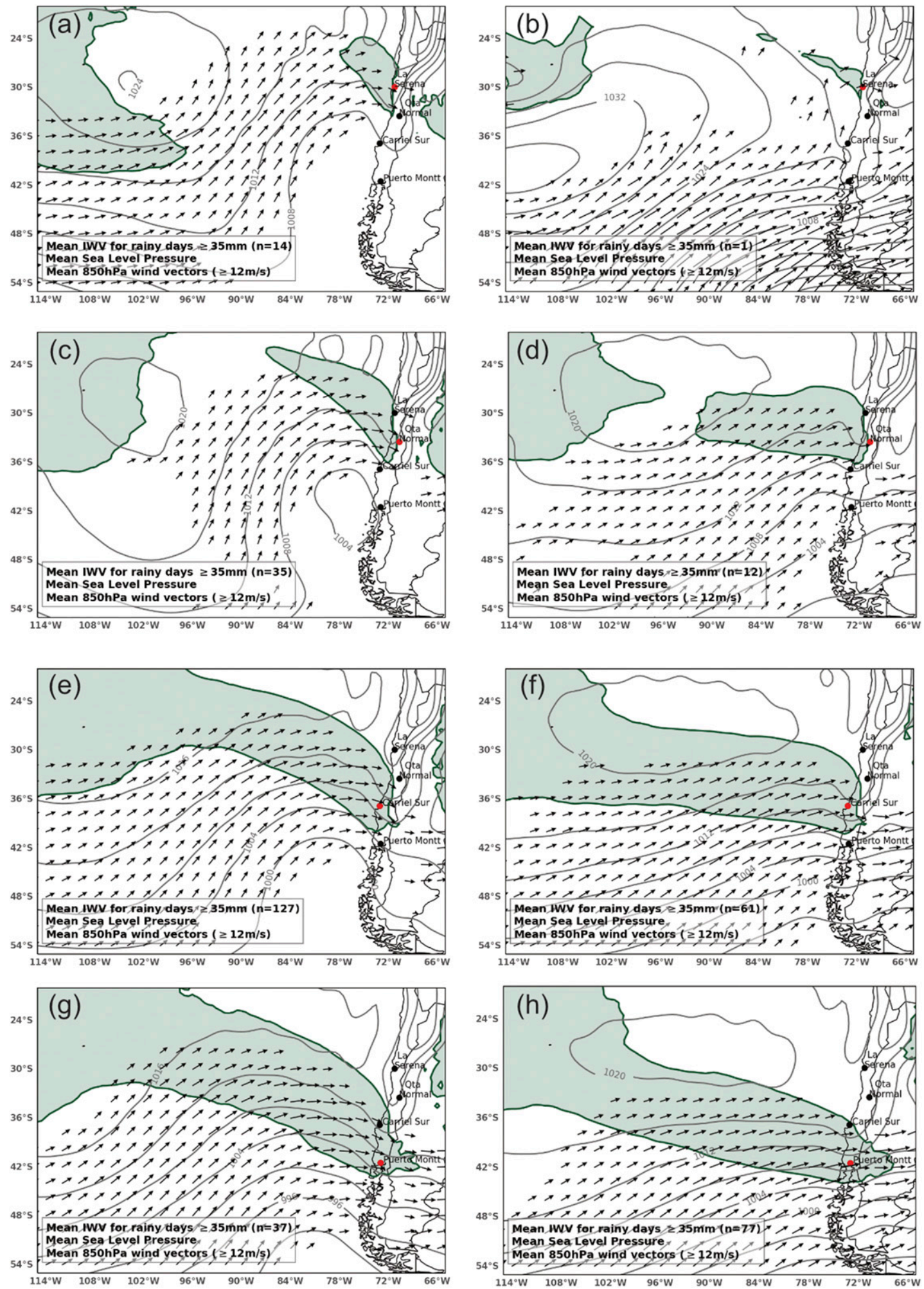

FIG. 11. As in Fig. 10, but for IWV $=26 \mathrm{~mm}$ (shaded contour), mean sea level pressure (gray contours), and wind vectors (a),(b) $\geq 10$; (c),(d) $\geq 12$; and (e)-(h) $\geq 14 \mathrm{~m} \mathrm{~s}^{-1}$. Note that (b) includes one event only (i.e., one day), and it is included for consistency. 

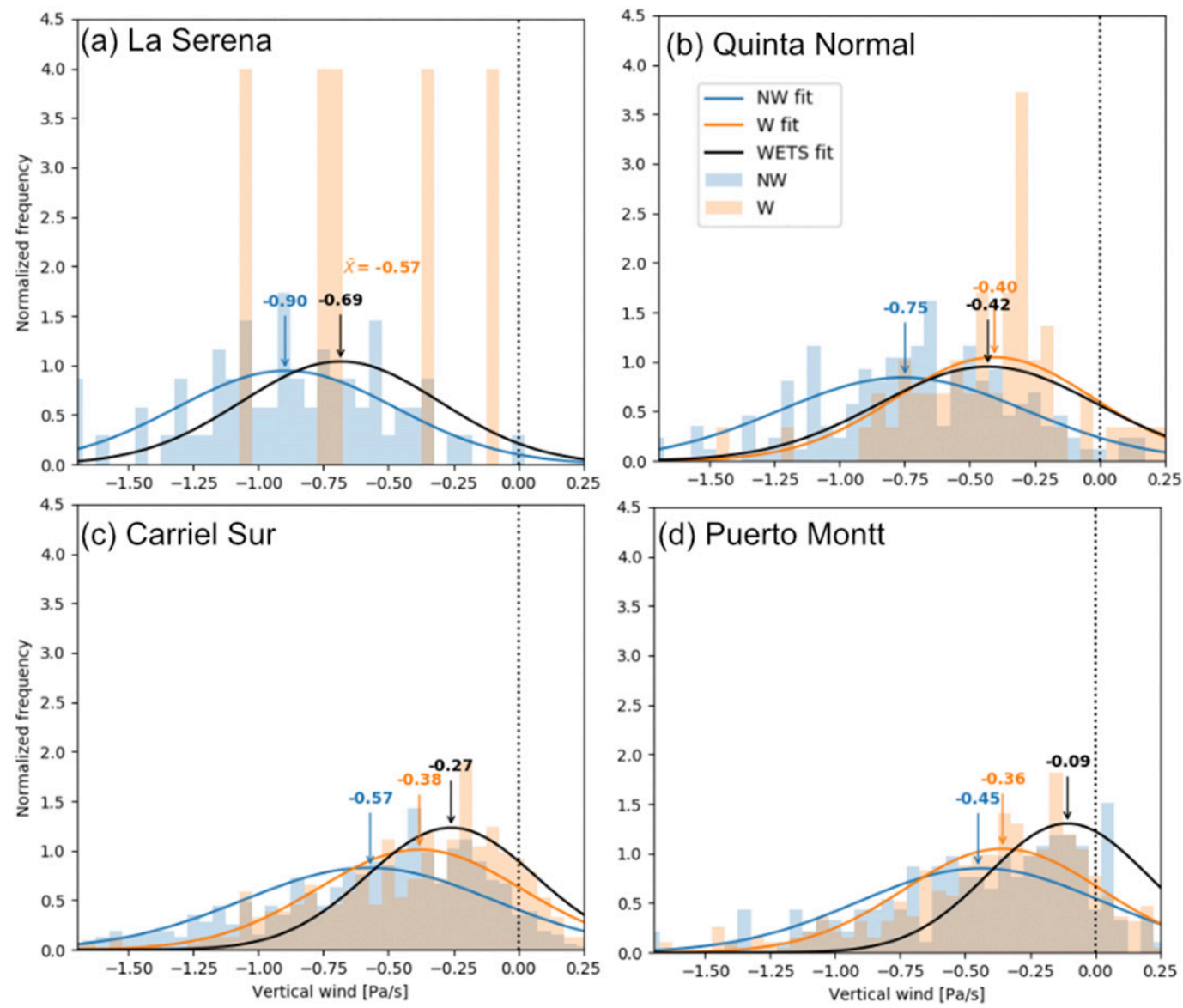

FIG. 12. Probability density functions of CFSR-derived vertical velocity $\left(\mathrm{Pa} \mathrm{s}^{-1}\right)$ for each reference location: (a) La Serena, (b) Quinta Normal, (c) Carriel Sur, and (d) Puerto Montt. Samples are extracted from their corresponding $1.5^{\circ} \times 1.5^{\circ}$ latitude-longitude box (Fig. 1). Bin width is $0.05 \mathrm{~Pa} \mathrm{~s}^{-1}$. Statistics are from 6-h steps within each IVT group presented in Fig. 8: NW (blue bars) and W (orange bars). Corresponding lines depict the Gaussian distribution of each group, except for the single W case in La Serena. The black Gaussian line shows the distribution of WET days as reference. The mean value of each distribution is included.

cases could explain higher temperatures near the surface. As result, vertical characteristics suggest more unstable synoptic-scale dynamics responsible for EPEs in NW, while EPEs in W cases, with either more stable or neutral characteristics, are more tightly associated with moist fluxes forced to ascend over elevated terrain, like the Andes Mountains. This result brings the question if ARs associated to $\mathrm{W}$ cases correspond to ARs normally observed in northern California, where Ralph et al. (2005) described a mean AR profile being nearly neutral below $3 \mathrm{~km}$ MSL.

\section{Hydroclimatic implications}

The mean vertical profiles in Fig. 13 suggest thermal differences in EPEs associated with NW and W cases. From a hydroclimatic perspective, this implies a difference in the freezing-level altitude associated with each group and therefore a change in the fraction of the basin that captures snow and rain, posing different hydroclimatic risk levels. Figure 14 indicates that relative to Quinta Normal, EPEs associated with the NW cases have an average freezing-level altitude of $2.43 \mathrm{~km}$, while $\mathrm{W}$ cases have an average of $2.72 \mathrm{~km}$, almost $12 \%$ higher. Relative to Carriel Sur, NW and W cases have average values of 2.47 and $2.67 \mathrm{~km}$, respectively, $8 \%$ higher in $\mathrm{W}$ cases. Along with higher average altitudes in the $\mathrm{W}$ cases, this group also has a larger fraction of freezing-level altitude above $3.0 \mathrm{~km}$, with $32 \%$ in Quinta Normal and 26\% in Carriel Sur (versus $13 \%$ and $19 \%$ in NW cases, respectively). Finally, it is worth noting that both NW and W cases separate from the WETs distribution, highlighting their thermal differences from the average rainfall event.

The exact impact that the change in the freezing-level altitude will have in a given basin will depend on the 
Profiles for CFSR 3x3-grid box
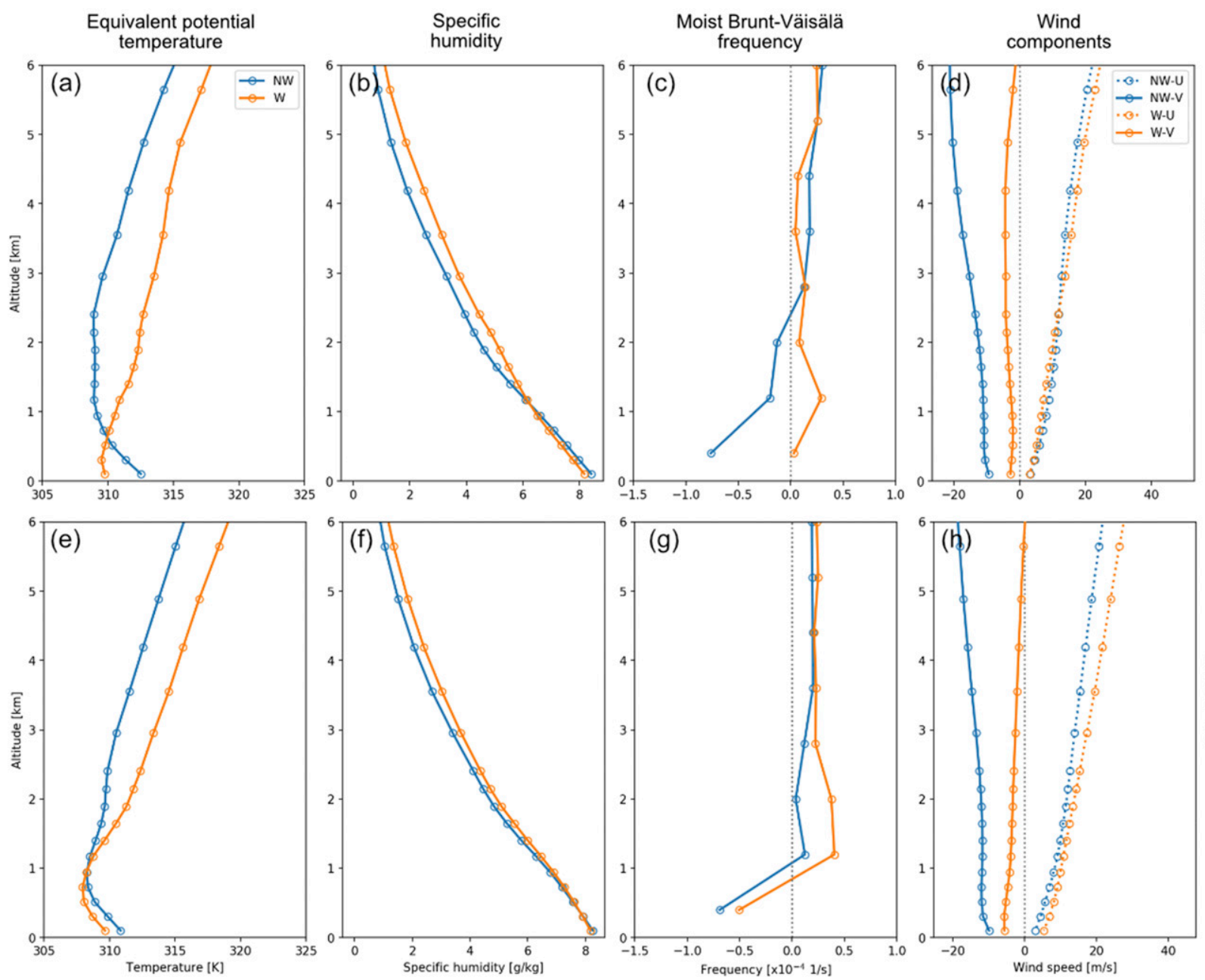

FIG. 13. CFSR-derived mean profiles of (a),(e) equivalent potential temperature; (b),(f) specific humidity; (c),(g) moist Brünt-Väisälä frequency; and (d),(h) wind components for two reference stations: (top) Quinta Normal and (bottom) Carriel Sur using their corresponding $1.5^{\circ} \times 1.5^{\circ}$ latitude-longitude box (Fig. 1).

basin area and altitude described by its hypsometric curve. For example, for the upper Maipo River basin, which drains just south of Quinta Normal from the Andes to the coast, the higher altitude in $\mathrm{W}$ cases would mean an increase of $8 \%$ in the area capturing rainfall instead of snow (Fig. 15). The same exercise applied to two other basins closer to Carriel Sur show an increment in the pluvial area between $8 \%$ and $16 \%$ (see Fig. S2).

The different forcing mechanism described for EPEs in the NW and W groups (e.g., synoptic versus orographic) would also imply differences in the median daily rainfall distribution, expecting a more widespread rainfall distribution in NW cases associated with enhanced instability and vertical velocity. As depicted in Fig. 16 for EPEs in Quinta Normal, the NW group seems to be associated with an area of median EPE rainfall $>60 \mathrm{~mm}$ over the Andes that has greater southward extent relative to the $\mathrm{W}$ group. Although surface observations along the Andes foothills apparently follow the same pattern as the CR2MET product (e.g., along the $60-\mathrm{mm}$ isoline), the scarcity of surface observations over the $>60 \mathrm{~mm}$-area prevents to confirm the CR2MET pattern. In addition, the NW group exhibits more rainfall over $40 \mathrm{~mm}$ spread from the Andes foothills coastward that is mostly in agreement with observations. By comparing the differences between NW and W rainfall, the NW group shows larger daily accumulations south of Quinta Normal over the Andes and also along the coast, while the $\mathrm{W}$ group mostly exhibits larger accumulations in a reduced area over the Andes west of Quinta Normal. Maximum median rainfall is observed at the latitude of Quinta 

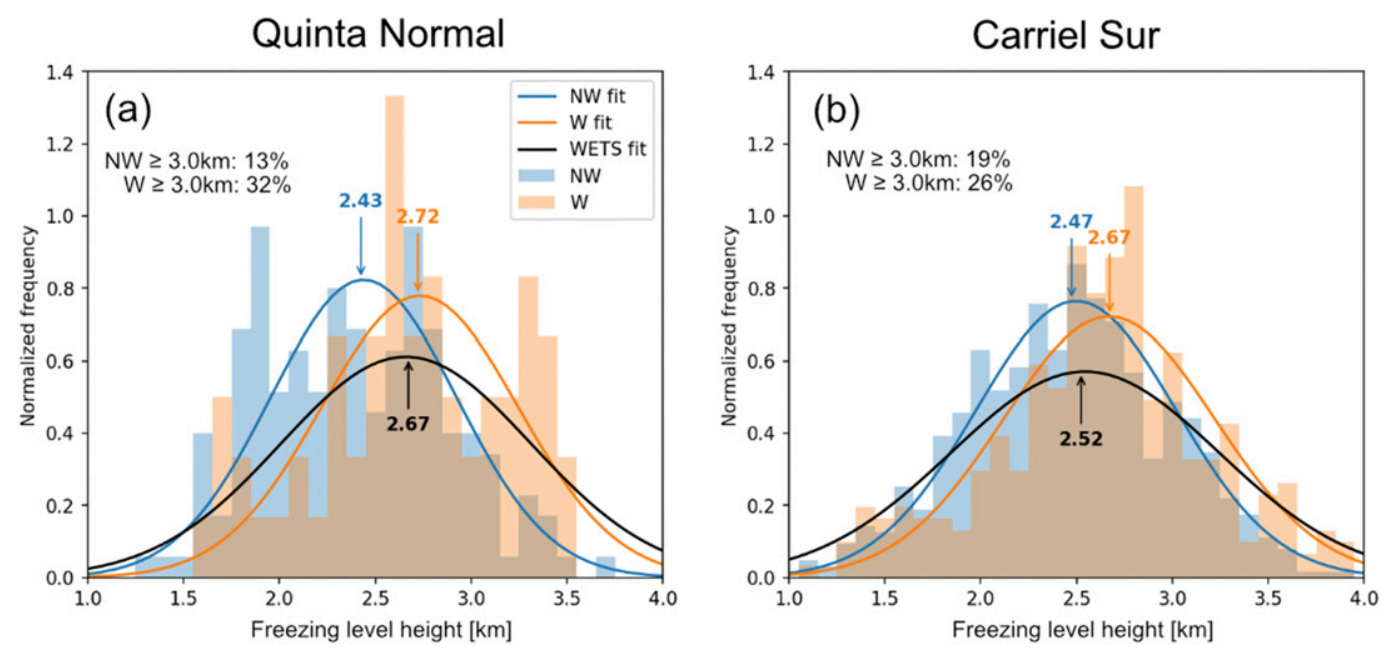

FIG. 14. Probability density functions of CFSR-derived $0^{\circ} \mathrm{C}$ isotherm height for (a) Quinta Normal and (b) Carriel Sur in their corresponding $1.5^{\circ} \times 1.5^{\circ}$ latitude-longitude box (Fig. 1). Statistics are from 6-h steps within each IVT group: NW (blue bars) and W (orange bars). Corresponding lines depict the Gaussian distribution of each IVT group. The black Gaussian line shows the distribution of WET days as reference. The mean value of each distribution is included.

Normal for W cases because storms make landfall at this latitude. As a result, and as showed in the previous section, the $\mathrm{W}$ synoptic pattern indicates strong zonal moisture fluxes along with a nearly neutral stratified atmosphere, such that the airflow can directly ascend over the Andes. On the other hand, the NW synoptic pattern is associated with a trough along the coast that forces northwesterly winds in a more unstable environment, such that the rainfall spreads from northwest to southeast relative to Quinta Normal location.

From a hydroclimatic risk perspective, the $\mathrm{W}$ rainfall could be considered more relevant for Quinta Normal owing to it directly affects the upper Maipo River basin and is also associated with a higher freezing-level altitude. Therefore, EPEs with $\mathrm{W}$ characteristics most likely will lead to floods and produce negative impacts for the city of Santiago, the most populated city in Chile. In a different example, if considering Carriel Sur as the reference station, the median daily rainfall field suggests a larger threat for EPEs with NW characteristics because they produce larger amounts along the coast, where Concepción, the largest city of this region, is located (see Fig. S3).

\section{Concluding remarks}

This study examined extreme daily rainfall in centralsouthern Chile and its relationship with synoptic conditions, especially low-level horizontal water vapor fluxes. To this end we have used long-term daily rainfall records encompassing 20-60 years from 347 rain gauges located between $26^{\circ}$ and $45^{\circ} \mathrm{S}$ and CFSR reanalysis products over the period 1979-2017.

The first driving motivation of this study was related with general characteristics of extreme rainfall. Extreme precipitation events (EPEs) in central-southern Chile were defined as daily events accumulating $\geq 35 \mathrm{~mm}$.

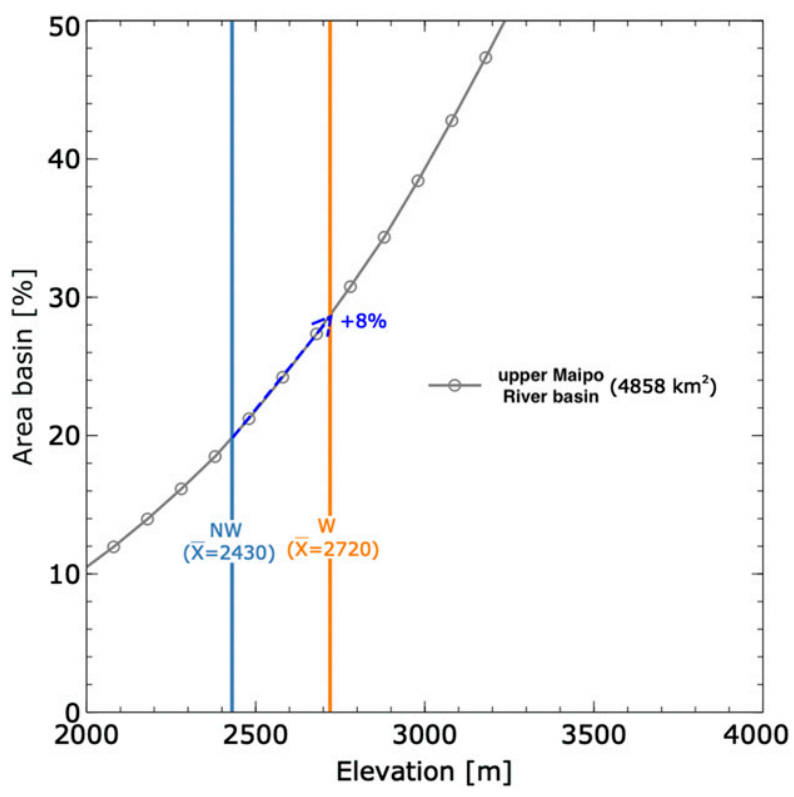

FIG. 15. Hypsometric curve (area below a given height) for upper Maipo River basin, nearby Quinta Normal station (see Fig. 16). The basin starts at an altitude of $1000 \mathrm{~m}$ MSL. Mean $0^{\circ} \mathrm{C}$ isotherm height for each IVT group (NW and W), the area of the basin, and the percentage of area change from NW to $\mathrm{W}$ are included. 

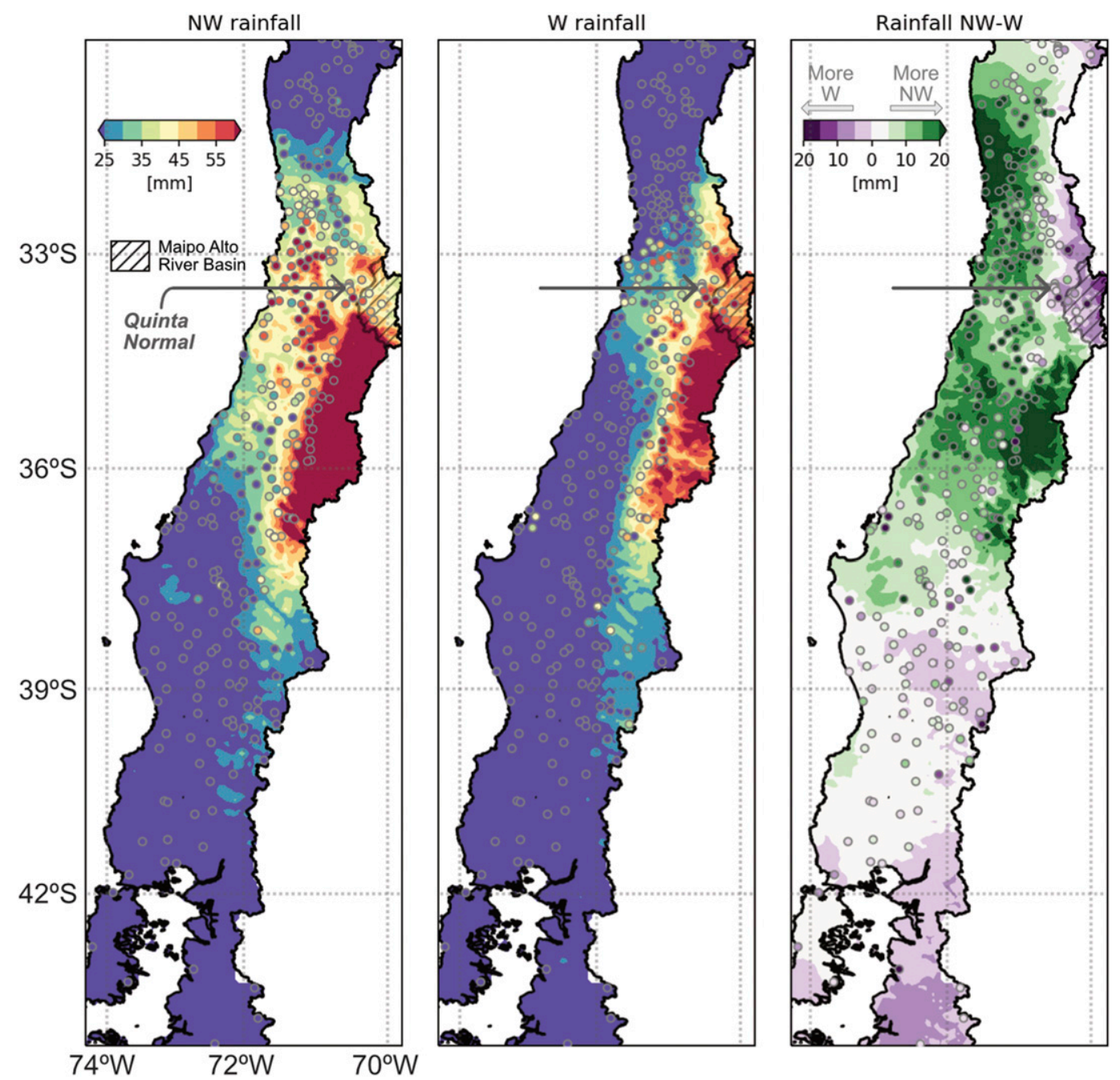

FIG. 16. Median rainfall derived from CR2MET (shaded contours) and from the CR2 database (circles) for IVT groups (a) NW and (b) W associated with EPE days at Quinta Normal and (c) the rainfall difference between these groups. The location of the upper Maipo River basin is included.

We found that EPEs occur within entire domain and follow an overall orographically forced pattern. Most of the extreme rainfall is observed during austral winter, especially north of $34^{\circ} \mathrm{S}$, and the events tend to last no more than one day. Extreme rainfall events impact a latitudinal range of $\sim 2^{\circ}(\sim 220 \mathrm{~km})$, and there is a southward bias of the rainfall spread when storms impact northward locations. A multilinear regression between IVT components (predictor) and EPE rainfall (predictand) can account a maximum of $40 \%$ of the variance. The relatively poor linear relationship compared with other studies (e.g., Neiman et al. 2002, 2009) could indicate that daily rainfall resolution is way too coarse to find a strong relationship, that unstable conditions have a larger role in extreme rainfall events observed in central-southern Chile, or both.
The second driving motivation was related with the synoptic environment of EPEs. Composited synoptic analyses identified EPE cases dominated by northwesterly (NW) and westerly (W) moisture fluxes, in agreement with previous studies. Key features of the NW group include a $300-\mathrm{hPa}$ trough projecting from extratropic to subtropics, a surface level depression, and cyclonic winds at $850-\mathrm{hPa}$ along the coast associated with IWV $>26 \mathrm{~mm}$. Conversely, the dominant features in the $\mathrm{W}$ group include both a very weak $300-\mathrm{hPa}$ trough and surface depression, as well as coastal westerly winds associated with IWV $>26 \mathrm{~mm}$. Indeed, the midlevel ascent just upstream of the coast-a proxy of the large-scale, geostrophic forcing-in NW cases is larger than in $\mathrm{W}$ cases, indicative a more prominent role of the forced ascent over the Andes in the later storms. 


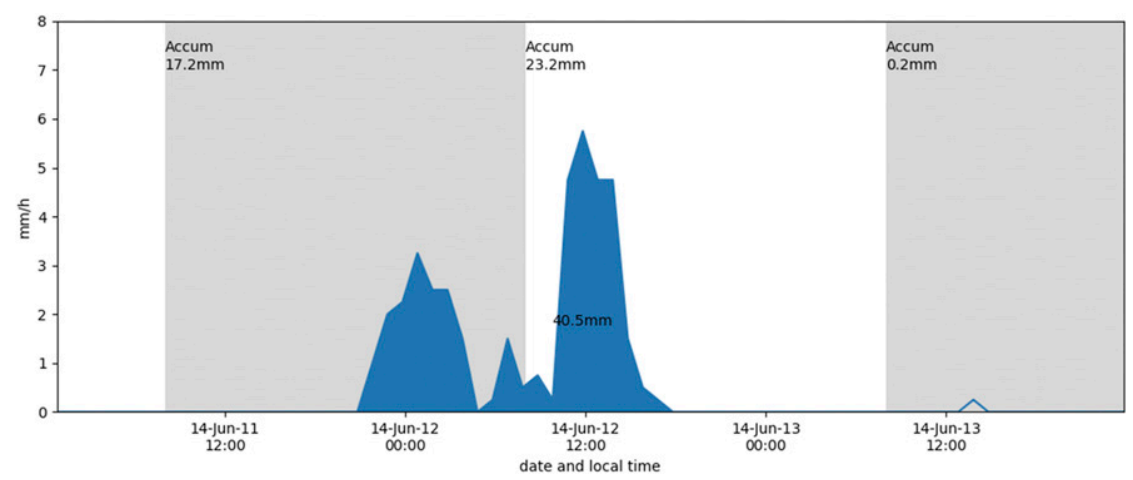

FIG. A1. Example of an EPE missed due to daily accumulation in fixed 24-h blocks (1200-1200 UTC or 0800-0800 LT). Gray areas show the daily accumulation while the blue shaded curve indicates the hourly rainfall accumulation. In this case, an EPE accumulating $40.5 \mathrm{~mm}$ is missed in the daily count because of splitting into two days with 17.2 and $23.2 \mathrm{~mm}$ each. Hourly rainfall observations are obtained from station Oficinas Centrales of Dirección General de Aguas in Santiago.

Despite the composited IWV of EPE cases indicates elongated structures resembling atmospheric rivers (AR), only between $27 \%$ and $70 \%$ of these cases correspond to an AR, with frequencies increasing southward. One hypothesis is that AR impact decreases northward because the most frequent AR landfall latitude is closer to $43^{\circ} \mathrm{S}$, especially during austral winter (Viale et al. 2018). Thus, toward the northern part of the domain cutoff lows likely contribute more frequently to extreme cases.

Examination of the vertical structures of NW and W composites indicates that $\mathrm{W}$ cases have warmer conditions above $1 \mathrm{~km}$ MSL, therefore presenting freezing levels at higher altitudes. As a result, we find two types of hydrometeorological impacts: W cases that can negatively impact Santiago (Quinta Normal station) through major floods and landslides in the upper Maipo River basin and NW cases that impose a threat to Concepción (Carriel Sur station) due to larger rainfall amounts are observed toward the coast. Thus, the hydroclimatic impact of NW and W cases depends on the location considered.

Despite that the synoptic structures presented here have been identified before for the entire set of rainfall days $\geq 1 \mathrm{~mm}$ in central Chile (e.g., Garreaud 2013), we show that westerly IVT cases (W cases) associated with extreme rainfall vary just slightly as a function of latitude. In other words, a storm with strong westerly IVT impacting southern Chile is similar in synoptic structure to a storm impacting central Chile. Yet, northwesterly IVT cases (NW cases) show significant variation depending on whether the baroclinic disturbance is landfalling in southern or central Chile. To the north of $35^{\circ} \mathrm{S}$ the number of $\mathrm{NW}$ cases reduces sharply and those producing an EPE feature strong synoptic forcing.
Future research should further explore the relationship between IVT and extreme rainfall in central-southern Chile, especially by performing field experiments that consider observations of collocated wind profiling radars, IWV derived from global positioning system (GPS) receivers, and rainfall at hourly level. This most likely would help to improve extreme rainfall forecast associated with orographic forcing. Numerical simulations should further explore the role of instabilities in extreme rainfall. Similarly, given contrasting results with the study of Viale and Garreaud (2015) regarding the frequency of rainfall over the Andes and potential artifacts due to rainfall accumulation in periods of $24 \mathrm{~h}$, the frequency of extreme rainfall events should be reexamined with hourly rain gauge observations.

Acknowledgments. This research was funded by CONICYT through FONDECYT Grant 3170155 and FONDAP Grant 15110009 . RV would like to thank Pablo Mendoza for valuable comments about DesInventar and Maximiliano Viale for providing the atmospheric river catalog. Two anonymous reviewers provided helpful comments that improved the final manuscript.

\section{APPENDIX}

\section{Daily and Hourly Rainfall Accumulations}

Daily rainfall observations are accumulated in fixed blocks of $24 \mathrm{~h}$, starting at 1200 UTC and ending at 1200 UTC of the following day. This counting technique complicates the estimation of an extreme rainfall event because it is biased by the fixed block. Figure A1 provides an example of an EPE crossing 1200 UTC that was 
missed in the daily rainfall account of events $\geq 35 \mathrm{~mm}$. Instead, labeling individual storms based on a minimum rainfall threshold and then counting its rainfall accumulation and duration retrieves a better estimate of event duration. With this context, hourly rainfall accumulation for three reference locations (Santiago, Concepción, and Puerto Montt) provided by Dirección General de Aguas (DGA) was examined. Storms were counted by considering a rainfall threshold $\geq 0.5 \mathrm{~mm}$ and a maximum of two consecutive hours with no rainfall. The statistics are included in Table S1.

\section{REFERENCES}

Alvarez-Garreton, C., and Coauthors, 2018: The CAMELS-CL dataset - Chile dataset. Hydrol. Earth Syst. Sci., 22, 5817-5846, https://doi.org/10.5194/hess-22-5817-2018.

American Meteorological Society, 2019: Atmospheric river. Glossary of Meteorology, http://glossary.ametsoc.org/ wiki/Atmospheric_river.

Azad, R., and A. Sorteberg, 2017: Extreme daily precipitation in coastal western Norway and the link to atmospheric rivers. J. Geophys. Res. Atmos., 122, 2080-2095, https://doi.org/ 10.1002/2016JD025615.

Barrett, B. S., R. Garreaud, and M. Falvey, 2009: Effect of the Andes Cordillera on precipitation from a midlatitude cold front. Mon. Wea. Rev., 137, 3092-3109, https://doi.org/10.1175/ 2009MWR2881.1.

Bozkurt, D., R. Rondanelli, R. Garreaud, and A. Arriagada, 2016: Impact of warmer eastern tropical Pacific SST on the March 2015 Atacama floods. Mon. Wea. Rev., 144, 4441-4460, https:// doi.org/10.1175/MWR-D-16-0041.1.

Center for Climate and Resilience Research, 2018: Datos de precipitación, continuing from 2017 (updated monthly). Subset used: cr2_prDaily_2018, Center for Climate and Resilience Research (CR2), accessed 1 May 2018, http://www.cr2.cl/ datos-de-precipitacion/?cp_Precipitacion $=2 \#$.

Falvey, M., and R. Garreaud, 2007: Wintertime precipitation episodes in central Chile: Associated meteorological conditions and orographic influences. J. Hydrometeor., 8, 171-193, https://doi.org/10.1175/JHM562.1.

Fuenzalida, H. A., R. Sánchez, and R. D. Garreaud, 2005: A climatology of cutoff lows in the Southern Hemisphere. J. Geophys. Res., 110, D18101, https://doi.org/10.1029/2005JD005934.

Garreaud, R., 2009: The Andes climate and weather. Adv. Geosci., 22, 3-11, https://doi.org/10.5194/adgeo-22-3-2009.

_ 2013: Warm winter storms in central Chile. J. Hydrometeor., 14, 1515-1534, https://doi.org/10.1175/JHM-D-12-0135.1.

— , and H. A. Fuenzalida, 2007: The influence of the Andes on cutoff lows: A modeling study. Mon. Wea. Rev., 135, 15961613, https://doi.org/10.1175/MWR3350.1.

—- P. Lopez, M. Minvielle, and M. Rojas, 2013: Large-scale control on the Patagonia climate. J. Climate, 26, 215-230, https://doi.org/10.1175/JCLI-D-12-00001.1.

Gimeno, L., and Coauthors, 2015: Major mechanisms of atmospheric moisture transport and their role in extreme precipitation events. Annu. Rev. Environ. Resour., 41, 1-25, https:// doi.org/10.1146/annurev-environ-110615-085558.

Grillakis, M., A. Koutroulis, J. Komma, I. Tsanis, W. Wagner, and G. Blöschl, 2016: Initial soil moisture effects on flash flood
generation-A comparison between basins of contrasting hydro-climatic conditions. J. Hydrol., 541, 206-217, https:// doi.org/10.1016/j.jhydrol.2016.03.007.

Guan, B., and D. E. Waliser, 2015: Detection of atmospheric rivers: Evaluation and application of an algorithm for global studies. J. Geophys. Res., 120, 12 514-12 535, https://doi.org/10.1002/ 2015JD024257.

Hoskins, B., and K. Hodges, 2005: A new perspective on Southern Hemisphere storm tracks. J. Climate, 18, 4108-4129, https:// doi.org/10.1175/JCLI3570.1.

Kirshbaum, D. J., B. Adler, N. Kalthoff, C. Barthlott, and S. Serafin, 2018: Moist orographic convection: Physical mechanisms and links to surface-exchange processes. Atmosphere, 9, 80, https://doi.org/10.3390/atmos9030080.

Lavers, D. A., and G. Villarini, 2013: The nexus between atmospheric rivers and extreme precipitation across Europe. Geophys. Res. Lett., 40, 3259-3264, https://doi.org/10.1002/ grl.50636.

Marulanda, M. C., O. D. Cardona, and A. H. Barbat, 2010: Revealing the socioeconomic impact of small disasters in Colombia using the DesInventar database. Disasters, 34, 552-570, https:// doi.org/10.1111/j.1467-7717.2009.01143.x.

Meehl, G. A., and Coauthors, 2000: An introduction to trends in extreme weather and climate events: observations, socioeconomic impacts, terrestrial ecological impacts, and model projections. Bull. Amer. Meteor. Soc., 81, 413-416, https://doi.org/ 10.1175/1520-0477(2000)081<0413:AITTIE > 2.3.CO;2.

Neiman, P., F. Ralph, A. White, D. Kingsmill, and P. Persson, 2002: The statistical relationship between upslope flow and rainfall in California's coastal mountains: Observations during CALJET. Mon. Wea. Rev., 130, 1468-1492, https://doi.org/ 10.1175/1520-0493(2002)130<1468:TSRBUF > 2.0.CO;2.

- A. White, F. Ralph, D. Gottas, and S. Gutman, 2009: A water vapour flux tool for precipitation forecasting. Proc. Inst. Civ. Eng.: Water Manage., 162, 83-94, https://doi.org/ 10.1680/wama.2009.162.2.83.

Panorska, A. K., A. Gershunov, and T. J. Kozubowski, 2007: From diversity to volatility: Probability of daily precipitation extremes. Nonlinear Dynamics in Geosciences, A. A. Tsonis and J. B. Elsner, Eds., Springer, 465-484, https://doi.org/10.1007/ 978-0-387-34918-3_26.

Ralph, M. F., P. J. Neiman, and R. Rotunno, 2005: Dropsonde observations in low-level jets over the northeastern Pacific Ocean from CALJET-1998 and PACJET-2001: Mean vertical-profile and atmospheric-river characteristics. Mon. Wea. Rev., 133, 889-910, https://doi.org/10.1175/MWR2896.1.

Ramos, A. M., R. M. Trigo, M. L. Liberato, and R. Tomé, 2015: Daily precipitation extreme events in the Iberian Peninsula and its association with atmospheric rivers. J. Hydrometeor., 16, 579-597, https://doi.org/10.1175/JHM-D-14-0103.1.

Saavedra, N., and A. J. Foppiano, 1992: Monthly mean pressure model for Chile. Int. J. Climatol., 12, 469-480, https://doi.org/ 10.1002/joc.3370120505.

_ , E. Müller, and A. Foppiano, 2002: Monthly mean rainfall frequency model for the central Chilean coast: some climatic inferences. Int. J. Climatol., 22, 1495-1509, https://doi.org/ $10.1002 /$ joc. 806 .

Saha, S., and Coauthors, 2010: The NCEP Climate Forecast System Reanalysis. Bull. Amer. Meteor. Soc., 91, 1015-1057, https:// doi.org/10.1175/2010BAMS3001.1.

Shields, C. A., and Coauthors, 2018: ARTMIP: project goals and experimental design. Geosci. Model Dev., 11, 2455-2474, https://doi.org/10.5194/gmd-11-2455-2018. 
Singleton, A. T., and C. J. Reason, 2007: A numerical model study of an intense cutoff low pressure system over South Africa. Mon. Wea. Rev., 135, 1128-1150, https://doi.org/10.1175/ MWR3311.1.

Trenberth, K. E., 1991: Storm tracks in the Southern Hemisphere. J. Atmos. Sci., 48, 2159-2178, https://doi.org/10.1175/15200469(1991)048<2159:STITSH >2.0.CO;2.

- 2011: Changes in precipitation with climate change. Climate Res., 47, 123-138, https://doi.org/10.3354/cr00953.

Valenzuela, R., and D. Kingsmill, 2015: Orographic precipitation forcing along the coast of Northern California during a landfalling winter storm. Mon. Wea. Rev., 143, 3570-3590, https:// doi.org/10.1175/MWR-D-14-00365.1.

Valenzuela, R. A., and D. E. Kingsmill, 2018: Terrain-trapped airflows and orographic rainfall along the coast of northern California. Part II: Horizontal and vertical structures observed by a scanning Doppler radar. Mon. Wea. Rev., 146, 2381-2402, https://doi.org/10.1175/MWR-D-170227.1.

Viale, M., and F. A. Norte, 2009: Strong cross-barrier flow under stable conditions producing intense winter orographic precipitation: A case study over the subtropical central Andes.
Wea. Forecasting, 24, 1009-1031, https://doi.org/10.1175/ 2009WAF2222168.1.

- and M. N. Nuñez, 2011: Climatology of winter orographic precipitation over the subtropical central Andes and associated synoptic and regional characteristics. J. Hydrometeor., 12, 481-507, https://doi.org/10.1175/2010JHM1284.1.

——, and R. Garreaud, 2015: Orographic effects of the subtropical and extratropical Andes on upwind precipitating clouds. J. Geophys. Res. Atmos., 120, 4962-4974, https:// doi.org/10.1002/2014JD023014.

_- R. Valenzuela, R. Garreaud, and F. M. Ralph, 2018: Impacts of atmospheric rivers on precipitation in southern South America. J. Hydrometeor., https://doi.org/10.1175/jhm-d-18-0006.1

Waliser, D., and B. Guan, 2017: Extreme winds and precipitation during landfall of atmospheric rivers. Nat. Geosci., 10, 179183, https://doi.org/10.1038/ngeo2894.

Wilks, D. S., 2011: Statistical Methods in the Atmospheric Sciences. 3rd ed. International Geophysics Series, Vol. 100, Academic Press, 704 pp.

WMO, 2014: Atlas of mortality and economic losses from weather, climate and water extremes (1970-2012). WMO-1123, 44 pp., https://library.wmo.int/pmb_ged/wmo_1123_en.pdf. 